Supporting Information for

\title{
Dependence of Effective Molarity on Linker Length for an Intramolecular Protein-Ligand System
}

\author{
Vijay M. Krishnamurthy, Vincent Semetey, Paul J. Bracher, Nan Shen, and \\ George M. Whitesides* \\ Department of Chemistry and Chemical Biology, Harvard University \\ 12 Oxford Street, Cambridge, MA 02138 \\ * Author to whom correspondence should be addressed. \\ Telephone: (617) 495-9430 \\ Fax: (617) 495-9857 \\ E-mail: gwhitesides@gmwgroup.harvard.edu
}




\section{Supporting Experimental Procedures}

General Considerations. Analytical HPLC was run on a Varian instrument with a C18 column (length $=250 \mathrm{~mm}$, i.d. $=4.6 \mathrm{~mm}, 5 \mu \mathrm{m}$ particle size) from Vydac using a linear gradient of water with $0.1 \%$ TFA (solvent $A$ ) followed by acetonitrile containing $0.08 \%$ TFA (solvent $B$ ), at a flow rate of $1.2 \mathrm{~mL} \mathrm{~min}^{-1}$ (UV detection at 214 and $254 \mathrm{~nm}$ ). Mass spectra were obtained by matrix-assisted laser desorption ionization/time-of-flight mass spectrometry (MALDI-TOF) on a Perspective Biosystems Voyager-DE PRO (Framingham, MA) using $\alpha$-cyano-4-

hydroxycinnamic acid as a matrix. High resolution electrospray ionization mass spectra (ESIMS) were obtained by using a Micromass LCT mass spectrometer (Beverly, MA) with a mass resolving power of 5,000 $(\mathrm{m} / \Delta \mathrm{m})$ by the Mass Spectrometry facility at the Harvard Department of Chemistry and Chemical Biology.

General Synthetic Considerations. Schemes S.1-S.5 show the syntheses of the molecules used in this study. The carboxylic acid $\mathbf{4}$ and mono-Boc-protected diamine 8 were prepared as previously described. ${ }^{1,2}$

SA-OMe (3). A commercial sample of 4-(aminomethyl)benzenesulfonamide (2.0 g, 10.7 mmol) was suspended in $100 \mathrm{~mL}$ of $\mathrm{CH}_{3} \mathrm{CN}$ in a $200-\mathrm{mL}$ round-bottomed flask. Triethylamine (1.8 $\mathrm{mL}, 12.9 \mathrm{mmol}$ ) was added to the flask, which was then fitted with a dropping funnel and lowered into an ice-water bath. A solution of methyl adipoyl chloride $(2,1.8 \mathrm{~mL}, 11.6 \mathrm{mmol})$ in $10 \mathrm{~mL}$ of $\mathrm{CH}_{2} \mathrm{Cl}_{2}$ was added dropwise over the course of $15 \mathrm{~min}^{3}$ The flask was allowed to warm to room temperature and the mixture was stirred for a total of $19 \mathrm{~h}$. The solvent was removed by rotary evaporation. The residual solid was suspended in $60 \mathrm{~mL}$ of $0.5 \mathrm{M} \mathrm{HCl}$ for 10 min, and then filtered through a sintered glass frit. The white solid was washed with $100 \mathrm{~mL}$ of deionized water and pumped dry under vacuum. Yield: $2.66 \mathrm{~g}(8.10 \mathrm{mmol}, 75 \%)$. White 
Scheme S.1. Synthesis of the SA-OMe (3), Pyr-SSEG 0 SA (7), and their intermediates.

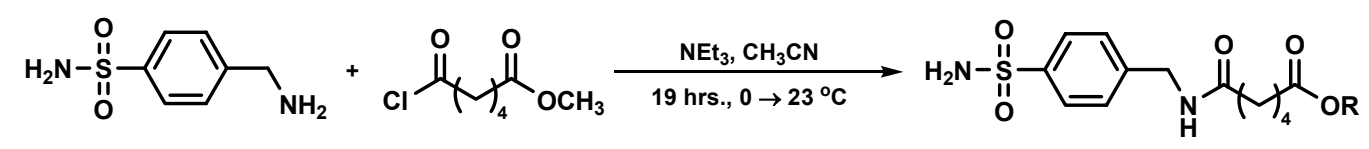

1

2
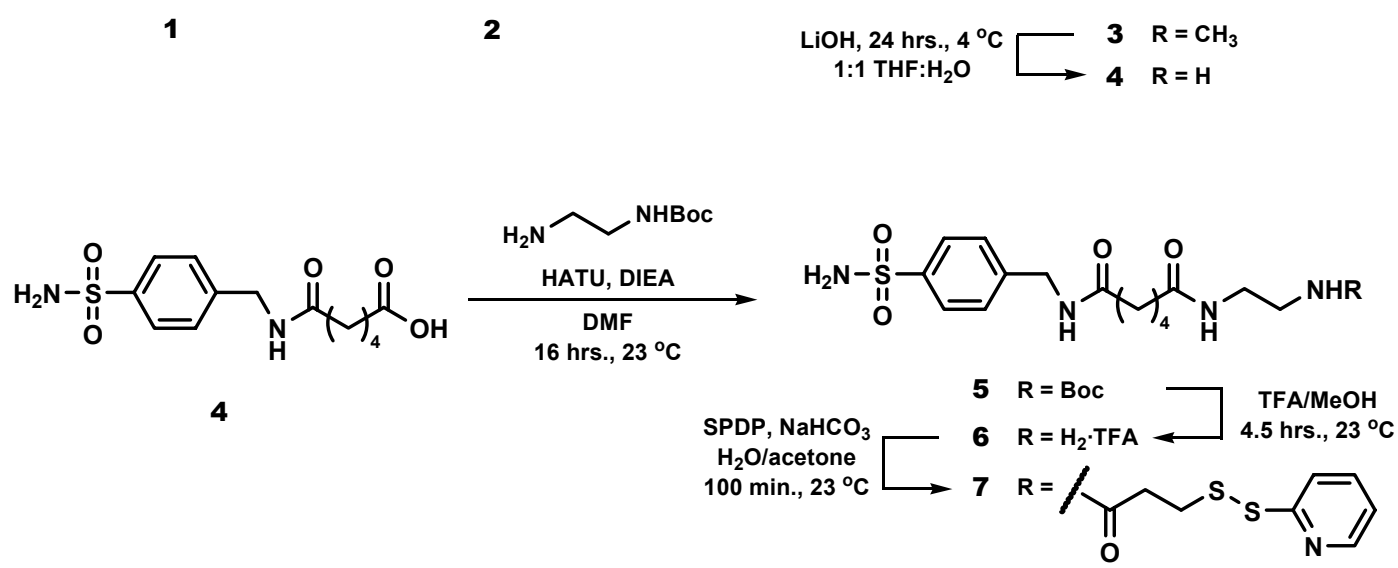
Scheme S.2. Synthesis of the Pyr-SSEG 2 SA (10) and its intermediates.

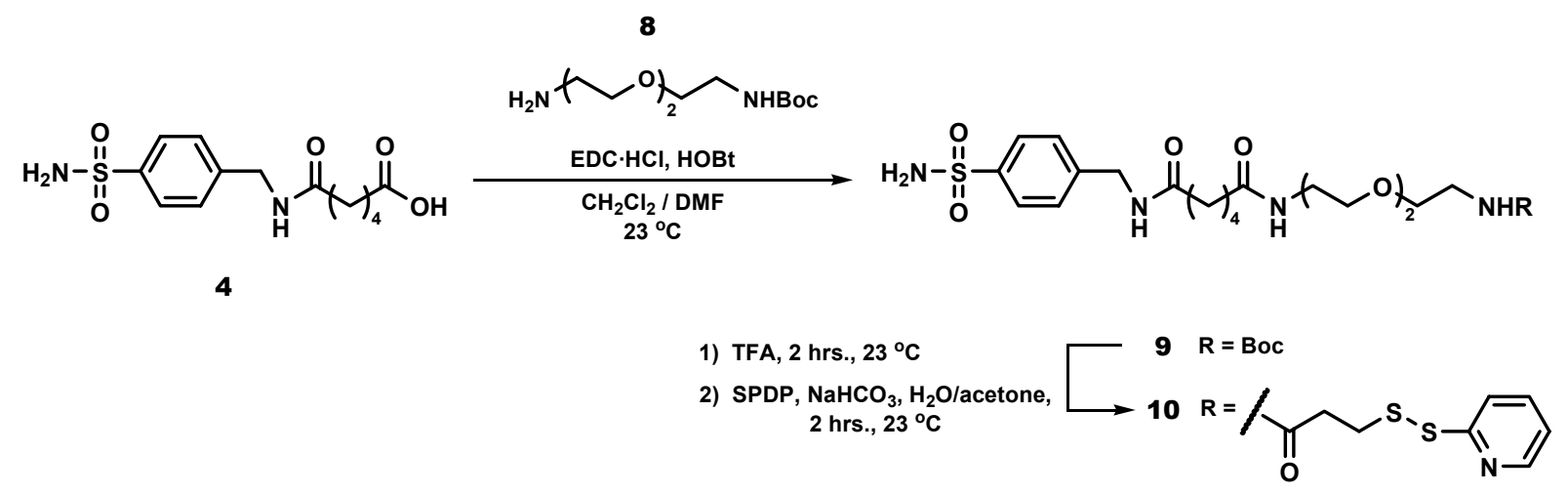


Scheme S.3. Synthesis of Pyr-SSEG 10 SA (17), Pyr-SSEG 20 SA (23), and their intermediates.

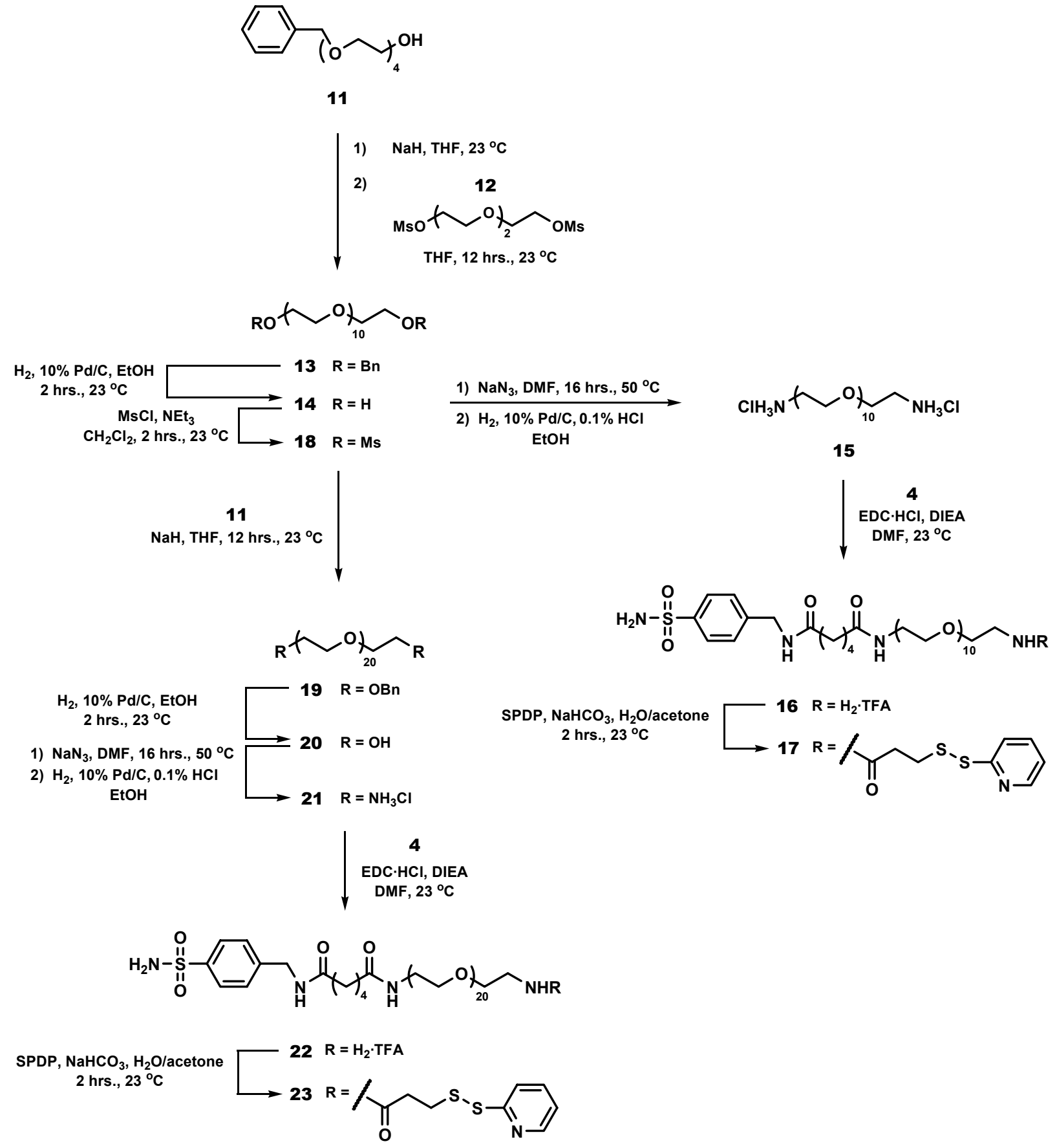


Scheme S.4. Synthesis of Pyr-SSEG 5 SA (27) and its intermediates.

$$
\text { } \overbrace{}^{\circ} \overbrace{R}
$$

1) $\mathrm{MsCl}, \mathrm{NEt}_{3}$

$\mathrm{CH}_{2} \mathrm{Cl}_{2}, 2 \mathrm{hrs}$., $23^{\circ} \mathrm{C} \quad 24 \mathrm{R}=\mathrm{OH}$

2) $\mathrm{NaN}_{3}, \mathrm{DMF}, 16$ hrs., $50^{\circ} \mathrm{C}$

3) $\mathrm{H}_{2}, 10 \% \mathrm{Pd} / \mathrm{C}, 0.1 \% \mathrm{HCl}$

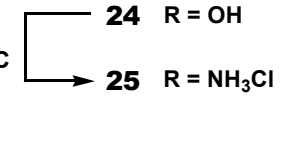

$\underset{\substack{\text { EDC. } \mathrm{HCl}, \text { DIEA } \\ \text { DMF, } 23^{\circ} \mathrm{C}}}{\stackrel{4}{\longrightarrow}}$<smiles>NS(=O)(=O)c1ccccc1</smiles>

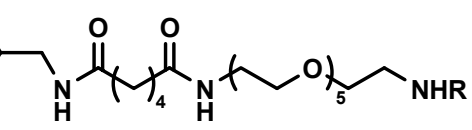

SPDP, $\mathrm{NaHCO}_{3}, \mathrm{H}_{2} \mathrm{O} /$ acetone

2 hrs., $23^{\circ} \mathrm{C}$

$26 \mathrm{R}=\mathrm{H}_{2} \cdot \mathrm{TFA}$

$\longrightarrow 27 \mathrm{R}=/ \prod_{0}{ }^{\mathrm{s}} \mathrm{s}$ 
Scheme S.5. Synthesis of Pyr-SSEG $2 \mathrm{CONH}_{2}$ (28).

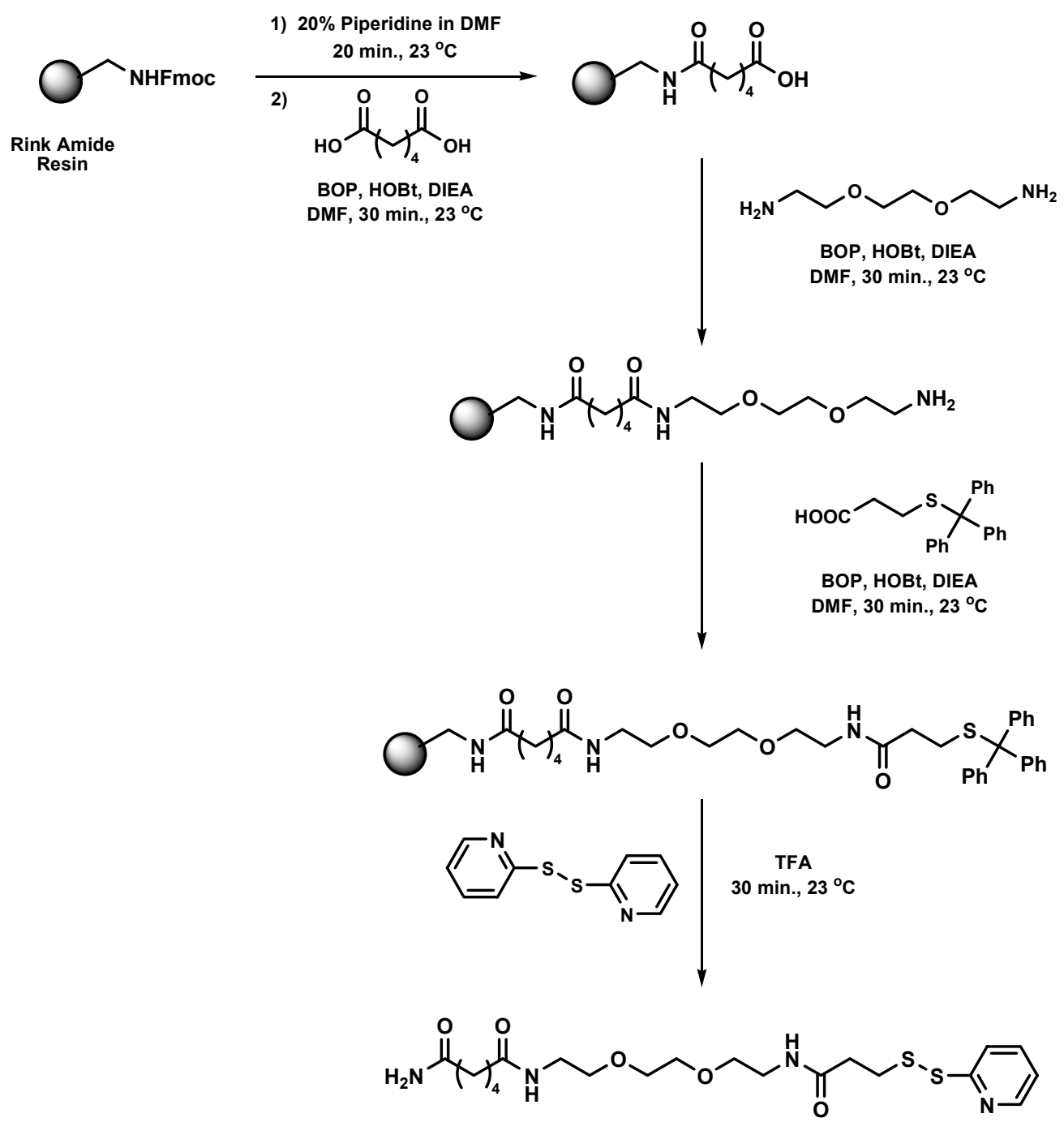

28 
powder. ${ }^{1} \mathrm{H}$ NMR (400 MHz, DMSO-d $\left.\mathrm{d}_{6}\right): \delta 8.39(\mathrm{t}, J=6.0 \mathrm{~Hz}, 1 \mathrm{H}), 7.74(\mathrm{~d}, J=8.2 \mathrm{~Hz}, 2 \mathrm{H})$, $7.38(\mathrm{~d}, J=8.5 \mathrm{~Hz}, 2 \mathrm{H}), 7.29$ (s, 2H), 4.29 (d, $J=6.0 \mathrm{~Hz}, 2 \mathrm{H}), 3.57$ (s, 3H), 2.30 (t, $J=7.0 \mathrm{~Hz}$, 2H), $2.14(\mathrm{t}, J=7.0 \mathrm{~Hz}, 2 \mathrm{H}), 1.51$ (m, 4H). ${ }^{13} \mathrm{C}$ NMR (126 MHz, DMSO-d 6 ): $\delta$ 173.96, 172.70, $144.54,143.23,128.12,126.35,51.92,42.32,35.58,33.68,25.36,24.76$. High Resolution ESIMS: 329.1168. Calculated for $\mathrm{C}_{14} \mathrm{H}_{21} \mathrm{~N}_{2} \mathrm{O}_{5} \mathrm{~S}^{+}\left[\mathrm{M}+\mathrm{H}^{+}\right]: 329.1166$.

Compound 4. Methyl ester 3 (2.5 g, $7.6 \mathrm{mmol})$ was suspended in $140 \mathrm{~mL}$ of THF in a $500-\mathrm{mL}$ round-bottomed flask. In a separate flask, $2.5 \mathrm{~g}$ of lithium hydroxide was dissolved in $140 \mathrm{~mL}$ of deionized water. Both mixtures were chilled to $4{ }^{\circ} \mathrm{C}$ and combined to form a turbid white mixture. After $1 \mathrm{~h}$ of stirring, the mixture had become homogeneous. After $24 \mathrm{~h}, 50 \mathrm{~mL}$ of $3 \mathrm{M} \mathrm{HCl}$ was added, and the mixture was allowed to warm to room temperature. Following the addition of a 100-mL portion of saturated aqueous $\mathrm{NaCl}$ solution, the mixture was extracted four times with $100-\mathrm{mL}$ portions of EtOAc, and the combined organic layers were evaporated. Yield: $2.28 \mathrm{~g}$ (7.25 mmol, 95\%). White powder. ${ }^{1} \mathrm{H}$ NMR (400 MHz, DMSO-d 6 ): $\delta 11.99$ (s, $1 \mathrm{H}), 8.39(\mathrm{t}, J=5.9 \mathrm{~Hz}, 1 \mathrm{H}), 7.74(\mathrm{~d}, J=8.5 \mathrm{~Hz}, 2 \mathrm{H}), 7.38(\mathrm{~d}, J=8.2 \mathrm{~Hz}, 2 \mathrm{H}), 7.28(\mathrm{~s}, 2 \mathrm{H})$, $4.29(\mathrm{~d}, J=6.0 \mathrm{~Hz}, 2 \mathrm{H}), 2.20(\mathrm{t}, J=6.9 \mathrm{~Hz}, 2 \mathrm{H}), 2.14(\mathrm{t}, J=7.0 \mathrm{~Hz}, 2 \mathrm{H}), 1.49(\mathrm{~m}, 4 \mathrm{H}) .{ }^{13} \mathrm{C}$ NMR (126 MHz, DMSO-d 6 ): $\delta$ 175.09, 172.76, 144.55, 143.22, 128.11, 126.36, 42.32, 35.68, 34.07, 25.47, 24.84. High Resolution ESI-MS: 315.1005. Calculated for $\mathrm{C}_{13} \mathrm{H}_{19} \mathrm{~N}_{2} \mathrm{O}_{5} \mathrm{~S}^{+}$ $\left[\mathrm{M}+\mathrm{H}^{+}\right]: 315.1009$.

Compound 5. Carboxylic acid 4 (500 mg, $1.59 \mathrm{mmol})$ was dissolved in $15 \mathrm{~mL}$ of dry DMF with stirring. $O$-(7-Azabenzotriazole-1-yl)- $N, N, N, N^{\prime}$-tetramethyluronium hexafluorophosphate (HATU, $665 \mathrm{mg}, 1.75 \mathrm{mmol}$ ) was added as a solid and the resulting clear solution was stirred for $10 \mathrm{~min}$ at room temperature. ${ }^{4} \mathrm{~N}$-Boc-ethylenediamine $(0.5 \mathrm{~mL}, 3.2 \mathrm{mmol})$ was injected and the resulting yellow solution was stirred for $20 \mathrm{~min}$ before $0.8 \mathrm{~mL}$ ( $4.6 \mathrm{mmol}$ ) of 
diisopropylethylamine (DIEA) was added by syringe. The mixture was stirred for $16 \mathrm{~h}$ at room temperature, at which point $150 \mathrm{~mL}$ of a saturated solution of $\mathrm{NaCl}$ was added. The mixture was cooled to $4{ }^{\circ} \mathrm{C}$ and the white precipitate was isolated by vacuum filtration over sintered glass and washed with $100 \mathrm{~mL}$ of deionized water. Yield: $695 \mathrm{mg}(1.5 \mathrm{mmol}, 96 \%)$. White powder. ${ }^{1} \mathrm{H}$ NMR (400 MHz, DMSO-d 6$): \delta 8.44(\mathrm{t}, J=6.0,1 \mathrm{H}), 7.83(\mathrm{t}, J=4.9,1 \mathrm{H}), 7.74(\mathrm{~d}, J=8.0,2 \mathrm{H})$, $7.38(\mathrm{~d}, J=8.0,2 \mathrm{H}), 7.30(\mathrm{~s}, 2 \mathrm{H}), 6.79(\mathrm{t}, J=5.3,1 \mathrm{H}), 4.28(\mathrm{~d}, J=5.9,2 \mathrm{H}), 3.02(\mathrm{~m}, 2 \mathrm{H}), 2.93$ (m, 2H), $2.12(\mathrm{t}, J=6.6,2 \mathrm{H}), 2.03(\mathrm{t}, J=6.6,2 \mathrm{H}), 1.46(\mathrm{~m}, 4 \mathrm{H}), 1.35(\mathrm{~s}, 9 \mathrm{H}) .{ }^{13} \mathrm{C} \operatorname{NMR}(101$ MHz, DMSO-d $\left.{ }_{6}\right): \delta 172.84,172.79,156.29,144.55,143.22,128.12,126.35,78.31,42.32,40.78$, $39.33,35.84,35.78,28.92,25.62$ (the signals from the two central adipoyl methylene carbons appear to be accidentally equivalent). High Resolution ESI-MS: 457.2118. Calculated for $\mathrm{C}_{20} \mathrm{H}_{33} \mathrm{~N}_{4} \mathrm{O}_{6} \mathrm{~S}^{+}\left[\mathrm{M}+\mathrm{H}^{+}\right]: 457.2115$.

Compound 6. The Boc-protected amine 5 (486 mg, $1.1 \mathrm{mmol}$ ) was suspended in $10 \mathrm{~mL}$ of trifluoroacetic acid with vigorous stirring at room temperature. After $3 \mathrm{~h}, 5 \mathrm{~mL}$ of methanol was added and the solution stirred for an additional $1.5 \mathrm{~h}$. The solvent was removed by rotary evaporation under high vacuum. The remaining solid was redissolved in $10 \mathrm{~mL}$ of methanol, evaporated, and placed on high vacuum overnight to remove the last vestiges of excess trifluoroacetic acid. Yield: $565 \mathrm{mg}$ (100\% based on loss of $t$-butyl signal in NMR). Clear oil with a faint brown hue. ${ }^{1} \mathrm{H}$ NMR (400 MHz, DMSO-d $\left.{ }_{6}\right): \delta 8.40(\mathrm{t}, J=5.9,1 \mathrm{H}), 7.97(\mathrm{t}, J=5.8$, 1H), 7.77 (s, br, 3H), 7.74 (d, $J=8.2,2 \mathrm{H}), 7.38$ (d, $J=8.5,2 \mathrm{H}), 7.29$ (s, 2H), 4.29 (d, $J=6.0$, 2H), $3.25(\mathrm{dd}, J=12.1,6.3,2 \mathrm{H}), 2.82(\mathrm{dd}, J=12.2,6.2,2 \mathrm{H}), 2.14(\mathrm{t}, J=6.9,2 \mathrm{H}), 2.08$ (t, $J=$ 6.9, 2H), 1.48 (m, 4H). ${ }^{13} \mathrm{C}$ NMR (101 MHz, DMSO-d 6 ): $\delta 173.57,172.84,155.88$ (q, $J=34.3$ ), $144.53,143.22,128.12,126.35,116.81$ (q, $J=294.5), 42.33,39.40,37.07,35.79,35.76,25.60$, 25.41. High Resolution ESI-MS: 357.1595. Calculated for $\mathrm{C}_{15} \mathrm{H}_{25} \mathrm{~N}_{4} \mathrm{O}_{4} \mathrm{~S}^{+}[\mathrm{M}+\mathrm{H}]^{+}: 357.1591$. 
Pyr-SSEG $_{0}$ SA (7). The full quantity of the trifluoroacetate salt of amine 6 (565 mg) was dissolved in $8 \mathrm{~mL}$ of $250 \mathrm{mM} \mathrm{NaHCO}_{3}$. A 5-mL solution of $N$-succinimidyl-3-(2-pyridyldithio)propionate (SPDP, $0.38 \mathrm{mmol}$ ) in acetone was added dropwise with rapid stirring. A precipitate formed within $10 \mathrm{~min}$ and the solution was stirred at room temperature for a total of $100 \mathrm{~min}$. The precipitate was isolated by vacuum filtration over a frit of sintered glass and washed with 25 $\mathrm{mL}$ of deionized water $(76 \mathrm{mg}, 0.14 \mathrm{mmol})$. A second batch of product (20 mg, $0.036 \mathrm{mmol})$ was isolated by allowing the acetone from the filtrate to evaporate and filtering the subsequent precipitate in the same manner as before. Combined yield: $96 \mathrm{mg}(0.17 \mathrm{mmol}, 45 \%)$. White powder. ${ }^{1} \mathrm{H}$ NMR (400 MHz, DMSO-d 6 ): $\delta 8.44(\mathrm{~m}, 1 \mathrm{H}), 8.39(\mathrm{t}, J=5.8,1 \mathrm{H}), 7.99(\mathrm{~m}, 1 \mathrm{H})$, 7.85-7.71 (m, 3H), $7.74(\mathrm{~d}, J=8.4,2 \mathrm{H}), 7.38(\mathrm{~d}, J=8.4,2 \mathrm{H}), 7.30(\mathrm{~s}, 2 \mathrm{H}), 7.23(\mathrm{ddd}, J=7.3$, $4.8,1.1,1 \mathrm{H}), 4.29(\mathrm{~d}, J=5.8,2 \mathrm{H}), 3.06(\mathrm{~m}, 4 \mathrm{H}), 2.99(\mathrm{t}, J=7.1,2 \mathrm{H}), 2.47(\mathrm{t}, J=7.0,2 \mathrm{H}), 2.12$ $(\mathrm{t}, J=6.6,2 \mathrm{H}), 2.03(\mathrm{t}, J=6.6,2 \mathrm{H}), 1.46(\mathrm{~m}, 4 \mathrm{H}) .{ }^{13} \mathrm{C}$ NMR $\left(101 \mathrm{MHz}, \mathrm{DMSO}-\mathrm{d}_{6}\right): \delta 172.85$, $172.78,170.63,159.86,150.28,144.53,143.22,138.51,128.12,126.36,121.86,119.81,42.34$, $39.16,38.89,35.89,35.80,35.34,34.65,25.61$ (the signals from the two central adipoyl methylene carbons appear to be accidentally equivalent). High Resolution ESI-MS: 554.1554. Calculated for $\mathrm{C}_{23} \mathrm{H}_{32} \mathrm{~N}_{5} \mathrm{O}_{5} \mathrm{~S}_{3}{ }^{+}[\mathrm{M}+\mathrm{H}]^{+}: 554.1560$.

Compound 9. Carboxylic acid $4(0.98 \mathrm{~g}, 3.1 \mathrm{mmol})$ and Boc-protected amine 8 (0.77 g, $3.1 \mathrm{mmol}$ ) were dissolved in $40 \mathrm{~mL}$ of methylene chloride containing $5 \mathrm{~mL}$ of DMF. Hydroxybenzotriazole (HOBt, $0.43 \mathrm{~g}, 3.1 \mathrm{mmol}$ ) and 1-Ethyl-3-[3dimethylaminopropyl]carbodiimide hydrochloride (EDC $\cdot \mathrm{HCl}, 0.595 \mathrm{~g}, 3.1 \mathrm{mmol})$ were added with stirring and the reaction was allowed to proceed at room temperature. The solution was evaporated under reduced pressure, and the residue was taken up in $100 \mathrm{~mL}$ of water, then extracted four times with 100-mL portions of ethyl acetate. The combined organic phases were 
washed sequentially with saturated solutions of ammonium chloride, sodium bicarbonate, and sodium chloride, then dried over magnesium sulfate and evaporated under reduced pressure. Purification by flash chromatography using 2:1 acetone/ethyl acetate as the eluent gave $0.953 \mathrm{~g}$ (57\%) of a white powder. RP-HPLC $t_{\mathrm{R}}=12.57 \mathrm{~min}$ (linear gradient, $0-100 \% B, 20 \mathrm{~min}$ ). ${ }^{1} \mathrm{H}$ NMR (400 MHz, DMSO-d $\left.{ }_{6}\right): \delta 8.38(\mathrm{t}, J=6.0,1 \mathrm{H}), 7.82(\mathrm{t}, J=5.8,1 \mathrm{H}), 7.74(\mathrm{~d}, J=8.2,2 \mathrm{H})$, $7.39(\mathrm{~d}, J=8.1,2 \mathrm{H}), 7.29(\mathrm{~s}, 2 \mathrm{H}), 6.75(\mathrm{t}, J=6.0,1 \mathrm{H}), 4.30(\mathrm{~d}, J=5.9,2 \mathrm{H}), 3.48(\mathrm{~s}, 4 \mathrm{H}), 3.37$ (m, 4H), $3.18(\mathrm{~m}, 2 \mathrm{H}), 3.04(\mathrm{~m}, 2 \mathrm{H}), 2.13(\mathrm{t}, J=6.8,2 \mathrm{H}), 2.06(\mathrm{t}, J=6.8,2 \mathrm{H}), 1.47(\mathrm{~m}, 4 \mathrm{H})$, $1.36(\mathrm{~s}, 9 \mathrm{H}) .{ }^{13} \mathrm{C}$ NMR $\left(101 \mathrm{MHz}, \mathrm{DMSO}-\mathrm{d}_{6}\right): \delta 172.12,172.02,155.56,143.84,142.48$, $127.40,125.65,77.56,69.50,69.42,69.14,41.62,38.42,35.12,35.07,28.20,24.97,24.94$. MS (MALDI-TOF) $m / z: 567.82$ and 583.85. Calculated for $\mathrm{C}_{24} \mathrm{H}_{40} \mathrm{~N}_{4} \mathrm{NaO}_{8} \mathrm{~S}^{+}[\mathrm{M}+\mathrm{Na}]^{+}: 567.65$ and for $\mathrm{C}_{24} \mathrm{H}_{40} \mathrm{KN}_{4} \mathrm{O}_{8} \mathrm{~S}^{+}[\mathrm{M}+\mathrm{K}]^{+}: 583.76$.

Pyr-SSEG 2 SA (10). Boc-protected amine $9(0.42 \mathrm{~g}, 0.93 \mathrm{mmol})$ was dissolved in $8 \mathrm{~mL}$ of trifluoroacetic acid and stirred for $2 \mathrm{~h}$ at room temperature. Water $(25 \mathrm{~mL})$ was added, and the solution was lyophilized to give the deprotected amine. The crude amine was dissolved in 19 $\mathrm{mL}$ of 250-mM aqueous sodium bicarbonate. A solution of $N$-succinimidyl-3-(2-pyridyldithio)propionate (SPDP, $0.29 \mathrm{~g}, 0.93 \mathrm{mmol}$ ) in $9 \mathrm{~mL}$ of acetone was added with stirring. The reaction was allowed to proceed for $2 \mathrm{~h}$, then the acetone was removed under vacuum. The product precipitated from the aqueous solution as a sticky solid; sonication converted the solid to a powder. The powder was filtered, dried, and recrystallized from hot acetone to give $0.47 \mathrm{~g}$ (78 $\%$ ) of a white solid. RP-HPLC $t_{\mathrm{R}}=11.64$ min (linear gradient, $0-100 \% B, 20 \mathrm{~min}$ ). ${ }^{1} \mathrm{H}$ NMR (400 MHz, DMSO-d $\left.)_{6}\right): \delta 8.43(\mathrm{~m}, 1 \mathrm{H}), 8.42(\mathrm{t}, J=6.0,1 \mathrm{H}), 8.02(\mathrm{~m}, 2 \mathrm{H}), 7.80(\mathrm{~m}, 2 \mathrm{H}), 7.72(\mathrm{~d}$, $J=8.2,2 \mathrm{H}), 7.36(\mathrm{~d}, J=8.3,2 \mathrm{H}), 7.27(\mathrm{~s}, 2 \mathrm{H}), 7.20(\mathrm{~m}, 1 \mathrm{H}), 4.27(\mathrm{~d}, J=5.9,2 \mathrm{H}), 3.46(\mathrm{~s}, 4 \mathrm{H})$, $3.35(\mathrm{~m}, 4 \mathrm{H}), 3.16(\mathrm{~m}, 4 \mathrm{H}), 2.97(\mathrm{t}, J=6.9,2 \mathrm{H}), 2.49(\mathrm{t}, J=7.0,2 \mathrm{H}), 2.11(\mathrm{t}, J=6.7,2 \mathrm{H}), 2.03$ 
$(\mathrm{t}, J=6.8,2 \mathrm{H}), 1.45(\mathrm{~m}, 4 \mathrm{H}) .{ }^{13} \mathrm{C}$ NMR $\left(101 \mathrm{MHz}, \mathrm{DMSO}-\mathrm{d}_{6}\right): \delta 172.13,172.04,169.86$, 151.48, 143.84, 142.52, 137.76, 127.36, 125.66, 121.18, 121.08, 119.11, 69.49, 69.14, 69.02, 41.61, 38.59, 38.41, 35.12, 35.07, 34.47, 34.04, 24.97. MS (MALDI-TOF) m/z: 664.80. Calculated for $\mathrm{C}_{27} \mathrm{H}_{39} \mathrm{~N}_{5} \mathrm{NaO}_{7} \mathrm{~S}_{3}^{+}[\mathrm{M}+\mathrm{Na}]^{+}: 664.81$.

$\mathrm{BnO}\left(\mathrm{CH}_{2} \mathrm{CH}_{2} \mathrm{O}\right)_{11} \mathrm{Bn}$ (13). To a solution of tetra(ethylene glycol) monobenzyl ether 11 (6.16 g, $21.66 \mathrm{mmol})$ in THF $(20 \mathrm{~mL})$ were added portions of NaH (a total of $1.82 \mathrm{~g}, 43.32$ $\mathrm{mmol})$ as a $57 \%$ dispersion in oil. Next, a solution of $12(3.06 \mathrm{~g}, 10 \mathrm{mmol})$ in THF $(10 \mathrm{~mL})$ was added to the mixture. The mixture was stirred for $12 \mathrm{~h}$ at room temperature and then evaporated to dryness. The residue was chromatographed $\left(\mathrm{SiO}_{2} ; \mathrm{EtOAc} \rightarrow 10 \% \mathrm{MeOH}\right.$ in EtOAc) to yield $13(2.2 \mathrm{~g}, 3.22 \mathrm{mmol}, 32 \%)$ as an oil. RP-HPLC $t_{\mathrm{R}}=17.80 \mathrm{~min}$ (linear gradient, $0-100 \% \mathrm{~B}, 20$ min). ${ }^{1} \mathrm{H}$ NMR (500 MHz, $\left.\mathrm{CDCl}_{3}\right): \delta$ 7.25-7.38 (m, 10H), $4.56(\mathrm{~s}, 4 \mathrm{H}), 3.72-3.60(\mathrm{~m}, 44 \mathrm{H}) . \mathrm{MS}$ (MALDI-TOF) $m / z: 705.10$ and 721.15. Calculated for $\mathrm{C}_{36} \mathrm{H}_{58} \mathrm{NaO}_{12}{ }^{+}[\mathrm{M}+\mathrm{Na}]^{+}: 705.84$ and for $\mathrm{C}_{36} \mathrm{H}_{58} \mathrm{KO}_{12}{ }^{+}[\mathrm{M}+\mathrm{K}]^{+}: 721.95$.

$\mathbf{H O}\left(\mathrm{CH}_{2} \mathrm{CH}_{2} \mathbf{O}\right)_{11} \mathbf{H}$ (14). The compound $\mathbf{1 3}(2.2 \mathrm{~g}, 3.22 \mathrm{mmol})$ and $10 \% \mathrm{Pd} / \mathrm{C}(250 \mathrm{mg})$ were combined in ethanol $(100 \mathrm{~mL})$. This mixture was hydrogenated at $23{ }^{\circ} \mathrm{C}$ for $2 \mathrm{~h}$. The mixture was then filtered through Celite, and the filter cake washed with $2 \times 10 \mathrm{~mL}$ EtOH. The resulting solution was evaporated to yield $\mathbf{1 4}(1.44 \mathrm{~g}, 2.86 \mathrm{mmol}, 89 \%)$ as an oil. ${ }^{1} \mathrm{H}$ NMR (500 $\left.\mathrm{MHz}, \mathrm{CDCl}_{3}\right): \delta 3.67-3.49(\mathrm{~m}, 44 \mathrm{H}), 3.32(\mathrm{~s}, 2 \mathrm{H}) .{ }^{13} \mathrm{C} \mathrm{NMR}\left(126 \mathrm{MHz}, \mathrm{CDCl}_{3}\right): \delta 72.94,70.73$, 70.70, 70.65, 70.59, 70.31, 61.67. MS (MALDI-TOF) $\mathrm{m} / \mathrm{z}: 525.10$ and 540.89. Calculated for $\mathrm{C}_{22} \mathrm{H}_{46} \mathrm{NaO}_{12}{ }^{+}[\mathrm{M}+\mathrm{Na}]^{+}: 525.59$ and for $\mathrm{C}_{22} \mathrm{H}_{46} \mathrm{KO}_{12}{ }^{+}[\mathrm{M}+\mathrm{K}]^{+}: 541.70$.

$\mathbf{B n O}\left(\mathrm{CH}_{2} \mathbf{C H}_{2} \mathbf{O}\right)_{21} \mathbf{B n}$ (19). The oligoethyleneglycol 14 (598 mg, $\left.1.19 \mathrm{mmol}\right)$ in $\mathrm{CH}_{2} \mathrm{Cl}_{2}$ $(10 \mathrm{~mL})$ was first converted to its dimesylate (18) by adding triethylamine ( $365 \mu \mathrm{L}, 2.62 \mathrm{mmol})$ and mesyl chloride $(207 \mu \mathrm{L}, 2.62 \mathrm{mmol})$ dropwise. The solution was stirred for $2 \mathrm{~h}$ and then 
washed with water $(3 \times 50 \mathrm{~mL})$, evaporated, and dried. To a solution of penta(ethylene glycol) monobenzyl ether $11(861 \mathrm{mg}, 2.62 \mathrm{mmol})$ in THF $(20 \mathrm{~mL})$ was added $\mathrm{NaH}$, in portions (111 $\mathrm{mg}, 2.75 \mathrm{mmol}$, total), as a $57 \%$ dispersion in oil. Next, a solution of the dimesylate $\mathbf{1 8}$ in THF $(10 \mathrm{~mL})$ was added to the mixture. The mixture was stirred for $12 \mathrm{~h}$ at room temperature and then evaporated to dryness. The residue was purified by HPLC (30-100\%) to yield 19 (724 mg, $0.64 \mathrm{mmol}, 54 \%$ ) as an oil. RP-HPLC $t_{\mathrm{R}}=13.92 \mathrm{~min}$ (linear gradient, $0-100 \% \mathrm{~B}, 20 \mathrm{~min}$ ). ${ }^{1} \mathrm{H}$ $\operatorname{NMR}\left(500 \mathrm{MHz}, \mathrm{CDCl}_{3}\right): \delta$ 7.38-7.24 (m, 10H), $4.56(\mathrm{~s}, 4 \mathrm{H}), 3.73-3.61(\mathrm{~m}, 84 \mathrm{H}) . \mathrm{MS}$ (MALDI-TOF) $m / z$ : 1146.4 and $1162.7[\mathrm{M}+\mathrm{K}]^{+}$. Calculated for $\mathrm{C}_{56} \mathrm{H}_{98} \mathrm{NaO}_{22}{ }^{+}[\mathrm{M}+\mathrm{Na}]^{+}$: 1146.38 and for $\mathrm{C}_{56} \mathrm{H}_{98} \mathrm{KO}_{22}{ }^{+}[\mathrm{M}+\mathrm{K}]^{+}: 1162.49$.

$\mathbf{H O}\left(\mathrm{CH}_{2} \mathrm{CH}_{2} \mathrm{O}\right)_{21} \mathrm{H}$ (20). The compound 19 (674 mg, $\left.0.6 \mathrm{mmol}\right)$ and $10 \% \mathrm{Pd} / \mathrm{C}(50 \mathrm{mg})$ were combined in ethanol $(40 \mathrm{~mL})$. This mixture was hydrogenated at $23{ }^{\circ} \mathrm{C}$ for $2 \mathrm{~h}$. The mixture was then filtered through Celite, the filter cake was washed with $2 \times 10 \mathrm{~mL}$ ethanol, and the resulting solution was evaporated to yield 20 (560 mg, $0.59 \mathrm{mmol}, 99 \%) .{ }^{1} \mathrm{H}$ NMR (500 $\left.\mathrm{MHz}, \mathrm{CD}_{3} \mathrm{OD}\right): \delta 3.80-3.55(\mathrm{~m}, 84 \mathrm{H}) .{ }^{13} \mathrm{C} \mathrm{NMR}\left(126 \mathrm{MHz}, \mathrm{CDCl}_{3}\right): \delta 72.74,70.75,70.72$, 70.48, 61.84. MS (MALDI-TOF) $m / z$ : 965.64 and 981.68. Calculated for $\mathrm{C}_{42} \mathrm{H}_{86} \mathrm{NaO}_{22}{ }^{+}$ $[\mathrm{M}+\mathrm{Na}]^{+}: 966.12$ and for $\mathrm{C}_{42} \mathrm{H}_{86} \mathrm{KO}_{22}{ }^{+}[\mathrm{M}+\mathrm{K}]^{+}: 982.23$.

General Procedure for the Conversion of Alcohols to Amines (14 to 15, 20 to 21, and 24 to 25). Our basic procedure for converting alcohols to amines was adapted from an example in the literature. ${ }^{5}$ Oligoethylene glycols were converted to their mesylates (mesyl chloride, triethylamine, dichloromethane), and the mesylates were displaced with sodium azide (DMF, overnight, $50^{\circ} \mathrm{C}$ ) and then hydrogenated (EtOH with $0.1 \% \mathrm{HCl}, \mathrm{Pd} / \mathrm{C}, \mathrm{H}_{2}$ ).

$\mathbf{H}_{2} \mathbf{N}\left(\mathbf{C H}_{2} \mathbf{C H}_{2} \mathbf{O}\right)_{5} \mathbf{C H}_{2} \mathbf{C H}_{2} \mathbf{N H}_{2} \bullet \mathbf{2 H C l}$ (25). ${ }^{1} \mathrm{H}$ NMR $\left(500 \mathrm{MHz}, \mathrm{CDCl}_{3}\right): \delta 3.80-3.48(\mathrm{~m}$, 24H). ${ }^{13} \mathrm{C} \mathrm{NMR}\left(126 \mathrm{MHz}, \mathrm{CDCl}_{3}\right): \delta 70.84,70.81,70.76,70.49,70.39,70.28,70.22,70.04$, 
67.05, 50.85. MS (MALDI-TOF) $m / z$ : 281.94. Calculated for $\mathrm{C}_{12} \mathrm{H}_{29} \mathrm{~N}_{2} \mathrm{O}_{5}{ }^{+}[\mathrm{M}+\mathrm{H}]^{+}: 281.37$.

$\mathbf{H}_{2} \mathbf{N}\left(\mathrm{CH}_{2} \mathbf{C H}_{2} \mathrm{O}\right){ }_{10} \mathbf{C H}_{2} \mathbf{C H}_{2} \mathbf{N H}_{2} \bullet \mathbf{2 H C l}(\mathbf{1 5}) .{ }^{1} \mathrm{H}$ NMR $\left(500 \mathrm{MHz}, \mathrm{CD}_{3} \mathrm{OD}\right): \delta 3.76(\mathrm{t}, J=$ $5.1 \mathrm{~Hz}, 4 \mathrm{H}), 3.73-3.63(\mathrm{~m}, 36 \mathrm{H}), 3.16(\mathrm{t}, J=5.1 \mathrm{~Hz}, 4 \mathrm{H}) .{ }^{13} \mathrm{C} \mathrm{NMR}\left(126 \mathrm{MHz}, \mathrm{CDCl}_{3}\right)$ : $\delta 70.38,70.30,70.28,70.26,70.20,69.95,66.93,39.99$. MS (MALDI-TOF) $m / z: 502.01$. Calculated for $\mathrm{C}_{22} \mathrm{H}_{49} \mathrm{~N}_{2} \mathrm{O}_{10}{ }^{+}[\mathrm{M}+\mathrm{H}]^{+}: 501.64$.

$\mathbf{H}_{2} \mathbf{N}\left(\mathrm{CH}_{2} \mathbf{C H}_{2} \mathbf{O}\right)_{20} \mathbf{C H}_{2} \mathbf{C H}_{2} \mathbf{N H}_{2}$ (21). ${ }^{1} \mathrm{H} \mathrm{NMR}\left(500 \mathrm{MHz}, \mathrm{CD}_{3} \mathrm{OD}\right): \delta 3.55-3.81$ (m, 80H), 3.22-3.16 (m, 4H). ${ }^{13} \mathrm{C} \mathrm{NMR}\left(126 \mathrm{MHz}, \mathrm{CDCl}_{3}\right): \delta$ 70.38, 70.30, 70.28, 70.26, 70.20, 69.95, 66.93. MS (MALDI-TOF) $m / z$ : 942.54. Calculated for $\mathrm{C}_{42} \mathrm{H}_{89} \mathrm{~N}_{2} \mathrm{O}_{20}{ }^{+}[\mathrm{M}+\mathrm{H}]^{+}: 942.17$.

Compound 16. To a solution of the acid 4 (10 mg, $32 \mu \mathrm{mol})$, 1-Ethyl-3-[3dimethylaminopropyl]carbodiimide hydrochloride (EDC $\cdot \mathrm{HCl}, 6 \mathrm{mg}, 32 \mu \mathrm{mol}$ ) and $\mathrm{N}, \mathrm{N}$ diisopropylethylamine (DIEA, $7 \mu \mathrm{L}, 64 \mu \mathrm{mol})$ in $5 \mathrm{~mL}$ of DMF, was added 15 (64 mg, 127 $\mu \mathrm{mol})$ with stirring and the reaction was allowed to proceed at room temperature. The crude product was purified by HPLC (linear gradient, $0-80 \% \mathrm{~B}, 40 \mathrm{~min}$ ) and lyophilized to afford 16 $(10 \mathrm{mg}, 11 \mu \mathrm{mol}, 35 \%)$ as a clear oil. RP-HPLC $t_{\mathrm{R}}=11.52 \mathrm{~min}$ (linear gradient, $0-100 \% B, 20$ min). ${ }^{1} \mathrm{H}$ NMR (500 MHz, $\left.\mathrm{CD}_{3} \mathrm{OD}\right): \delta 7.85(\mathrm{~d}, J=8.3 \mathrm{~Hz}, 2 \mathrm{H}), 7.44(\mathrm{~d}, J=8.3 \mathrm{~Hz}, 2 \mathrm{H}), 4.43$ (s, 2H), 3.80-3.74 (m, 2H), 3.73-3.57 (m, 36H), 3.56-3.50 (m, 2H), 3.37-3.32 (m, 2H), 3.22-3.16 (m, 2H), $2.28(\mathrm{t}, J=6.8 \mathrm{~Hz}, 2 \mathrm{H}), 2.21(\mathrm{t}, J=6.8 \mathrm{~Hz}, 2 \mathrm{H}), 1.71-1.57(\mathrm{~m}, 4 \mathrm{H})$. MS (MALDI-TOF) $m / z:$ 798.32. Calculated for $\mathrm{C}_{35} \mathrm{H}_{65} \mathrm{~N}_{4} \mathrm{O}_{14} \mathrm{~S}^{+}[\mathrm{M}+\mathrm{H}]^{+}: 797.98$.

Pyr-SSEG 10 SA (17). The compound $16(9 \mathrm{mg}, 11.3 \mu \mathrm{mol})$ was dissolved in $230 \mu \mathrm{L}$ of $250 \mathrm{mM}$ aqueous sodium bicarbonate. A solution of $N$-succinimidyl-3-(2-pyridyldithio)propionate (SPDP, $3.5 \mathrm{mg}, 11.3 \mu \mathrm{mol}$ ) in $109 \mu \mathrm{L}$ of acetone was added with stirring. The reaction was allowed to proceed for $2 \mathrm{~h}$, at which point the acetone was removed under vacuum. The aqueous solution was neutralized and purified by RP-HPLC (linear gradient, 0-100\% $B, 40$ 
$\min$ ) to yield $17(4 \mathrm{mg}, 4 \mu \mathrm{mol}, 36 \%)$ as an oil. RP-HPLC $t_{\mathrm{R}}=14.54 \mathrm{~min}$ (linear gradient, 0 $100 \% \mathrm{~B}, 20 \mathrm{~min}) .{ }^{1} \mathrm{H}$ NMR (500 MHz, $\left.\mathrm{CD}_{3} \mathrm{OD}\right): \delta 8.42(\mathrm{~d}, J=4.9 \mathrm{~Hz}, 1 \mathrm{H}), 7.88-7.83(\mathrm{~m}, 4 \mathrm{H})$, $7.45(\mathrm{~d}, J=8.3 \mathrm{~Hz}, 2 \mathrm{H}), 7.29-7.23(\mathrm{~m}, 1 \mathrm{H}), 4.43(\mathrm{~s}, 2 \mathrm{H}), 3.72-3.59(\mathrm{~m}, 36 \mathrm{H}), 3.55-3.49(\mathrm{~m}, 4 \mathrm{H})$, 3.37-3.32 (m, 4H), 3.07 (t, $J=6.8 \mathrm{~Hz}, 2 \mathrm{H}), 2.63(\mathrm{t}, J=6.8 \mathrm{~Hz}, 2 \mathrm{H}), 2.28(\mathrm{t}, J=6.8 \mathrm{~Hz}, 2 \mathrm{H})$, $2.22(\mathrm{t}, J=6.8 \mathrm{~Hz}, 2 \mathrm{H}), 1.70-1.58(\mathrm{~m}, 4 \mathrm{H})$. MS (MALDI-TOF) $\mathrm{m} / z$ : 994.22 and 1016.04. Calculated for $\mathrm{C}_{43} \mathrm{H}_{72} \mathrm{~N}_{5} \mathrm{O}_{15} \mathrm{~S}_{3}{ }^{+}[\mathrm{M}+\mathrm{H}]^{+}: 995.25$ and for $\mathrm{C}_{43} \mathrm{H}_{71} \mathrm{~N}_{5} \mathrm{NaO}_{15} \mathrm{~S}_{3}{ }^{+}[\mathrm{M}+\mathrm{Na}]^{+}$: 1017.19.

Compound 22. To a solution of the acid 4 (6 mg, $19 \mu \mathrm{mol}), 1$-Ethyl-3-[3dimethylaminopropyl]carbodiimide hydrochloride (EDC $\cdot \mathrm{HCl}, 4 \mathrm{mg}, 19 \mu \mathrm{mol}$ ) and $\mathrm{N}, \mathrm{N}$ diisopropylethylamine (DIEA, $2 \mu \mathrm{L}, 19 \mu \mathrm{mol}$ ) in $5 \mathrm{~mL}$ of DMF, were added 21 (72 mg, 76 $\mu$ mol) with stirring and the reaction was allowed to proceed at room temperature. The crude product was purified by HPLC (linear gradient, $0-80 \% B, 40 \mathrm{~min}$ ) and lyophilized to afford 22 (8 $\mathrm{mg}, 6 \mu \mathrm{mol}, 31 \%$ ) as a clear oil. RP-HPLC $t_{\mathrm{R}}=16.68 \mathrm{~min}$ (linear gradient, $0-100 \% B, 20 \mathrm{~min}$ ). ${ }^{1} \mathrm{H}$ NMR (500 MHz, $\left.\mathrm{CD}_{3} \mathrm{OD}\right): \delta 7.85$ (d, $\left.J=8.3 \mathrm{~Hz}, 2 \mathrm{H}\right), 7.44$ (d, $\left.J=8.3 \mathrm{~Hz}, 2 \mathrm{H}\right), 4.43$ (s, 2H), 3.80-3.74 (m, 2H), 3.73-3.57 (m, 76H), 3.55-3.49 (m, 2H), 3.37-3.32 (m, 2H), 3.20-3.12 (m, 2H), $2.28(\mathrm{t}, J=6.8 \mathrm{~Hz}, 2 \mathrm{H}), 2.22(\mathrm{t}, J=6.8 \mathrm{~Hz}, 2 \mathrm{H}), 1.69-1.59(\mathrm{~m}, 4 \mathrm{H})$. MS (MALDI-TOF) $m / z$ : 1238.78. Calculated for $\mathrm{C}_{55} \mathrm{H}_{105} \mathrm{~N}_{4} \mathrm{O}_{24} \mathrm{~S}^{+}[\mathrm{M}+\mathrm{H}]^{+}$: 1238.51 .

Pyr-SSEG 20 SA (23). Amine $22(6 \mathrm{mg}, 4.5 \mu \mathrm{mol})$ was dissolved in $92 \mu \mathrm{L}$ of $250 \mathrm{mM}$ aqueous sodium bicarbonate. A solution of $N$-succinimidyl-3-(2-pyridyldithio)-propionate (SPDP, $1.4 \mathrm{mg}, 4.5 \mu \mathrm{mol}$ ) in $45 \mu \mathrm{L}$ of acetone was added with stirring. The reaction was allowed to proceed for $2 \mathrm{~h}$, at which point the acetone was removed under vacuum and the aqueous solution was neutralized. The product was purified by RP-HPLC (linear gradient, 0$100 \% \mathrm{~B}, 40 \mathrm{~min}$ ) to yield $\mathbf{2 3}\left(2 \mathrm{mg}, 1.4 \mu \mathrm{mol}, 31 \%\right.$ ) as an oil. RP-HPLC $t_{\mathrm{R}}=18.72 \mathrm{~min}$ (linear gradient, $0-100 \% B, 20 \mathrm{~min}) .{ }^{1} \mathrm{H}$ NMR (500 MHz, $\left.\mathrm{CD}_{3} \mathrm{OD}\right): \delta 8.45-8.41(\mathrm{~m}, 1 \mathrm{H}), 7.90-7.81(\mathrm{~m}$, 
4H), $7.47(\mathrm{~d}, J=8.3 \mathrm{~Hz}, 2 \mathrm{H}), 7.28-7.23(\mathrm{~m}, 1 \mathrm{H}), 4.45(\mathrm{~s}, 2 \mathrm{H}), 3.70-3.60(\mathrm{~m}, 76 \mathrm{H}), 3.57-3.51(\mathrm{~m}$, 4H), 3.41-3.36 (m, 4H), $3.08(\mathrm{t}, J=6.8 \mathrm{~Hz}, 2 \mathrm{H}), 2.65(\mathrm{t}, J=6.8 \mathrm{~Hz}, 2 \mathrm{H}), 2.30(\mathrm{t}, J=6.8 \mathrm{~Hz}$, 2H), $2.24(\mathrm{t}, J=6.8 \mathrm{~Hz}, 2 \mathrm{H}), 1.72-1.62(\mathrm{~m}, 4 \mathrm{H})$. MS (MALDI-TOF) $m / z: 1455.56$ and 1471.52 . Calculated for $\mathrm{C}_{63} \mathrm{H}_{111} \mathrm{~N}_{5} \mathrm{NaO}_{25} \mathrm{~S}_{3}{ }^{+}[\mathrm{M}+\mathrm{Na}]^{+}: 1457.76$ and $\mathrm{C}_{63} \mathrm{H}_{111} \mathrm{KN}_{5} \mathrm{O}_{25} \mathrm{~S}_{3}{ }^{+}[\mathrm{M}+\mathrm{K}]^{+}: 1473.87$.

Compound 26. To a solution of acid 4 (23 mg, $73 \mathrm{mmol})$, 1-Ethyl-3-[3dimethylaminopropyl]carbodiimide hydrochloride (EDC $\cdot \mathrm{HCl}, 14 \mathrm{mg}, 73 \mu \mathrm{mol}$ ), and $\mathrm{N}, \mathrm{N}$ diisopropylethylamine (DIEA, $13 \mu \mathrm{L}, 146 \mu \mathrm{mol}$ ) in $5 \mathrm{~mL}$ of DMF was added 25 (82 mg, 292 $\mu \mathrm{mol}$ ) with stirring, and the reaction was allowed to proceed at room temperature. The solution was evaporated to dryness. The crude product was purified by HPLC (linear gradient, $0-80 \% B$, $40 \mathrm{~min})$ and lyophilized to afford $\mathbf{2 6}(20 \mathrm{mg}, 29 \mu \mathrm{mol}, 40 \%)$ as a clear oil. RP-HPLC $t_{\mathrm{R}}=8.93$ min (linear gradient, $0-100 \% \mathrm{~B}, 20 \mathrm{~min}) .{ }^{1} \mathrm{H} \mathrm{NMR}\left(500 \mathrm{MHz}, \mathrm{CD}_{3} \mathrm{OD}\right): \delta 7.87(\mathrm{~d}, J=8.3 \mathrm{~Hz}$, 2H), $7.47(\mathrm{~d}, J=8.3 \mathrm{~Hz}, 2 \mathrm{H}), 4.45(\mathrm{~s}, 2 \mathrm{H}), 3.75(\mathrm{t}, J=5.4 \mathrm{~Hz}, 2 \mathrm{H}), 3.72-3.61(\mathrm{~m}, 16 \mathrm{H}), 3.56(\mathrm{t}$, $J=5.4 \mathrm{~Hz}, 2 \mathrm{H}), 3.38(\mathrm{t}, J=4.9 \mathrm{~Hz}, 2 \mathrm{H}), 3.15(\mathrm{t}, J=4.9 \mathrm{~Hz}, 2 \mathrm{H}), 2.33-2.28(\mathrm{~m}, 2 \mathrm{H}), 2.26-2.20$ (m, 2H), 1.71-1.59 (m, 4H). ${ }^{13} \mathrm{C}$ NMR (126 MHz, $\left.\mathrm{CD}_{3} \mathrm{OD}\right): \delta 70.27,70.22,70.12,70.06,70.04$, $69.96,69.80,69.47,66.72,42.50,42.39,39.45,39.00,35.55,35.51,25.36,25.31$. MS (MALDITOF) $m / z$ : 577.38 and 599.44. Calculated for $\mathrm{C}_{25} \mathrm{H}_{45} \mathrm{~N}_{4} \mathrm{O}_{9} \mathrm{~S}^{+}[\mathrm{M}+\mathrm{H}]^{+}: 577.72$ and for $\mathrm{C}_{25} \mathrm{H}_{44} \mathrm{NaN}_{4} \mathrm{O}_{9} \mathrm{~S}^{+}[\mathrm{M}+\mathrm{Na}]^{+}: 599.69$.

Pyr-SSEG ${ }_{20}$ SA (27). The amine 26 (9 mg, $\left.15.6 \mu \mathrm{mol}\right)$ was dissolved in $320 \mu \mathrm{L}$ of 250 $\mathrm{mM}$ aqueous sodium bicarbonate. A solution of $N$-succinimidyl-3-(2-pyridyldithio)-propionate (SPDP, $5 \mathrm{mg}, 15.6 \mu \mathrm{mol}$ ) in $150 \mu \mathrm{L}$ of acetone was added with stirring. The reaction was allowed to proceed for $2 \mathrm{~h}$. The acetone was removed under vacuum and the aqueous solution was neutralized and purified by RP-HPLC (linear gradient, $0-100 \%$ B, $40 \mathrm{~min}$ ) to yield 27 (6 $\mathrm{mg}$, $7.7 \mu \mathrm{mol}, 50 \%$ ) as an oil. RP-HPLC $t_{\mathrm{R}}=10.89 \mathrm{~min}$ (linear gradient, $0-100 \% B, 20 \mathrm{~min}$ ). ${ }^{1} \mathrm{H}$ 
NMR (500 MHz, $\left.\mathrm{CD}_{3} \mathrm{OD}\right): \delta 8.49-8.45(\mathrm{~m}, 1 \mathrm{H}), 7.93-7.90(\mathrm{~m}, 2 \mathrm{H}), 7.87(\mathrm{~d}, J=8.3,2 \mathrm{H}), 7.46$

(d, $J=8.3,2 \mathrm{H}), 7.34-7.30(\mathrm{~m}, 1 \mathrm{H}), 4.45(\mathrm{~s}, 2 \mathrm{H}), 3.70-3.60(\mathrm{~m}, 16 \mathrm{H}), 3.58-3.53(\mathrm{~m}, 4 \mathrm{H}), 3.41-$ $3.35(\mathrm{~m}, 4 \mathrm{H}), 3.10(\mathrm{t}, J=6.8 \mathrm{~Hz}, 2 \mathrm{H}), 2.65(\mathrm{t}, J=6.8 \mathrm{~Hz}, 2 \mathrm{H}), 2.30(\mathrm{t}, J=6.8 \mathrm{~Hz}, 2 \mathrm{H}), 2.23(\mathrm{t}, J$ $=6.8 \mathrm{~Hz}, 2 \mathrm{H}), 1.71-1.61(\mathrm{~m}, 4 \mathrm{H})$. MS (MALDI-TOF) $m / z: 774.95$ and 797.07. Calculated for $\mathrm{C}_{33} \mathrm{H}_{52} \mathrm{~N}_{5} \mathrm{O}_{10} \mathrm{~S}_{3}^{+}[\mathrm{M}+\mathrm{H}]^{+}: 774.98$ and for $\mathrm{C}_{33} \mathrm{H}_{51} \mathrm{~N}_{5} \mathrm{NaO}_{10} \mathrm{~S}_{3}^{+}[\mathrm{M}+\mathrm{Na}]^{+}: 796.96$.

Pyr-SSEG $2 \mathbf{C O N H}_{2}$ (28). Pyr-SSEG ${ }_{2} \mathrm{CONH}_{2}(\mathbf{2 8})$ was synthesized using a stepwise solid-phase methodology. Assembly of the molecule was carried out on a 50- $\mu \mathrm{mol}$ scale starting from Rink-amide MBHA resin. ${ }^{6}$ The Fmoc group was removed using 20\% piperidine in DMF (1 $\times 5 \mathrm{~min}, 1 \times 15 \mathrm{~min}$ ) under nitrogen bubbling. The resin was then filtered and washed with DMF $(6 \times 3 \mathrm{~min})$. A solution of adipic acid (10 equiv.), BOP (10 equiv.), and HOBt (10 equiv.) in DMF and DIEA were added successively to the resin, and suspension was mixed for $30 \mathrm{~min}$, followed by extensive washings with DMF. 2,2'-(Ethylenedioxy)diethylamine (10 equiv.) was coupled using BOP (10 equiv.), HOBt (10 equiv.), and DIEA for 30 min and the resin was washed with DMF, and then $\operatorname{TrtS}\left(\mathrm{CH}_{2}\right)_{2} \mathrm{CO}_{2} \mathrm{H}$ (5 equiv.) was coupled with BOP (5 equiv.), HOBt (5 equiv.), and DIEA (9 equiv.) in DMF for 30 min. The resin was washed with $\mathrm{CH}_{2} \mathrm{Cl}_{2}$ and $\mathrm{Et}_{2} \mathrm{O}$, then dried under nitrogen. Thiol deprotection/activation and cleavage from the resin was performed by treatment with a mixture of TFA $(5 \mathrm{~mL})$ and 2,2'-Dipyridyl disulfide (10 equiv.) for 30 min. After evaporation, purification by RP-HPLC (linear gradient, $0-80 \% B, 40$ min) and lyophilization gave $\mathbf{2 8}(3 \mathrm{mg}, 13 \%)$ as a white powder. RP-HPLC $t_{\mathrm{R}}=12.76 \mathrm{~min}$ (linear gradient, $0-100 \% \mathrm{~B}, 20 \mathrm{~min}) .{ }^{1} \mathrm{H}$ NMR $\left(400 \mathrm{MHz}, \mathrm{CD}_{3} \mathrm{OD}\right): \delta 8.45-8.42(\mathrm{~m}, 1 \mathrm{H}), 7.91-$ $7.87(\mathrm{~m}, 2 \mathrm{H}), 7.32-7.27(\mathrm{~m}, 1 \mathrm{H}), 3.59(\mathrm{~s}, 4 \mathrm{H}), 3.55-3.49(\mathrm{~m}, 4 \mathrm{H}), 3.39-3.31(\mathrm{~m}, 4 \mathrm{H}), 3.07(\mathrm{t}, J=$ 6.8, 2H), $2.63(\mathrm{t}, J=6.8,2 \mathrm{H}), 2.20(\mathrm{~m}, 4 \mathrm{H}), 1.66-1.55(\mathrm{~m}, 4 \mathrm{H})$. MS (MALDI-TOF) $m / z: 473.9$. Calculated for $\mathrm{C}_{20} \mathrm{H}_{33} \mathrm{~N}_{4} \mathrm{O}_{5} \mathrm{~S}_{2}^{+}[\mathrm{M}+\mathrm{H}]^{+}: 473.62$. 


\section{Purification of $\mathrm{HCA}^{* *}{ }_{-} \mathrm{SSEG}_{10} \mathrm{SA}$ for Isothermal Titration Calorimetry. Crude}

$\mathrm{HCA}^{* *}{ }_{-} \mathrm{SSEG}_{10} \mathrm{SA}(\sim 5 \mathrm{mg})$ was incubated (with gentle shaking at $25^{\circ} \mathrm{C}$ ) with $200 \mu \mathrm{L}$ of benzenesulfonamide-conjugated agarose (Sigma) in $2 \mathrm{~mL}$ of sodium phosphate buffer $\mathrm{pH}$ 7.5. After $\sim 2 \mathrm{~h}$, the supernatant was isolated by centrifugation $(\sim 200 \times \mathrm{g}, 15 \mathrm{~min})$. UV analysis of the supernatant revealed that $\sim 10 \%$ of total protein was lost by this procedure. The sample was analyzed by fluorescence spectroscopy for the binding of DNSA (see next section) to determine the amount of unmodified $\mathrm{HCA}^{* *}$ present. $\mathrm{HCA}^{* *}$ was present as $<1 \%$ of total protein.

Determination of Dissociation Constants for the Binding of DNSA to HCA**. To the wells of a black microwell plate were added DNSA (which was two-fold diluted across the wells of the plate) and $\mathrm{HCA}^{* *}, \mathrm{HCA}^{* *}-\mathrm{SCH}_{2} \mathrm{CO}_{2}{ }^{-}$, or $\mathrm{HCA}^{* *}-\mathrm{SSEG}_{2} \mathrm{CONH}_{2}(50-100 \mathrm{nM})$ in a final volume of $200 \mu \mathrm{L}$ of $20 \mathrm{mM}$ sodium phosphate $\mathrm{pH}$ 7.5. The plate was allowed to incubate at 25 ${ }^{\circ} \mathrm{C}$ for $1 \mathrm{~h}$, and then its fluorescence was measured (excitation wavelength $=290 \mathrm{~nm}$ and emission wavelength $=460 \mathrm{~nm}$, with a $455 \mathrm{~nm}$ cut-off filter). Wells were read $\sim 30$ times. Fluorescence intensities $(F)$ were fit to eq S.1 (originally derived by Burton et al. in ref 18 of main text); this equation does not make the assumption that the concentration of free DNSA (that not bound to CA) is equal to that of total DNSA.

$$
F=F_{\text {min }}+\left(F_{\max }-F_{\min }\right)\left(\frac{K_{\mathrm{d}}+[\mathrm{CA}]_{\text {total }}+[\mathrm{DNSA}]_{\text {total }}-\sqrt{\left(K_{\mathrm{d}}+[\mathrm{CA}]_{\text {total }}+[\mathrm{DNSA}]_{\text {total }}\right)^{2}-4[\mathrm{CA}]_{\text {total }}[\mathrm{DNSA}]_{\text {total }}}}{2[\mathrm{CA}]_{\text {total }}}\right)
$$

$[\mathrm{CA}]_{\text {total }}$ and $[\mathrm{DNSA}]_{\text {total }}$ are the total concentrations of $\mathrm{HCA}^{* *}$ and DNSA, respectively. $F_{\min }$ is a constant to take into background fluorescence, $F_{\max }$ is the maximum fluorescence at total saturation of CA by DNSA, and $K_{\mathrm{d}}$ is the dissociation constant for the HCA-DNSA complex. $[\mathrm{CA}]_{\text {total }}$ was contrained to its known value, and the other parameters were allowed to vary to 
optimize the non-linear least squares fit (Origin). The value of $F_{\min }$ was very close to zero in all of the experiments.

Determination of Unmodified HCA** Contaminating HCA**-SSEG ${ }_{n}$ SA. To the wells of a black microwell plate were added 0-100 nM HCA** and $5 \mu \mathrm{M}$ DNSA, in $200 \mu \mathrm{L}$ of $20 \mathrm{mM}$ sodium phosphate buffer $\mathrm{pH}$ 7.5. The fluorescence of the plate was measured under conditions in which only the HCA**-DNSA complex was fluorescent (excitation wavelength = $290 \mathrm{~nm}$ and emission wavelength $=460 \mathrm{~nm}$, with a $455 \mathrm{~nm}$ cut-off filter). Figure S.4 shows these data with a linear fit. To determine the contamination by unmodified HCA** in the samples of $\mathrm{HCA}^{* *}{ }_{-} \mathrm{SSEG}_{n} \mathrm{SA}, \mathrm{HCA}^{* *}{ }_{-} \mathrm{SSEG}_{n} \mathrm{SA}$ was added to the wells of the plate containing $5 \mu \mathrm{M}$ DNSA, to a final concentration of 0.5 or $1.0 \mu \mathrm{M}$ in $200 \mu \mathrm{L}$ of $20 \mathrm{mM}$ sodium phosphate buffer $\mathrm{pH} 7.5$, and the fluorescence measured (as above). After subtraction of the fluorescence of the $\mathrm{HCA}^{* *}-\mathrm{SSEG}_{n} \mathrm{SA}$ protein alone (i.e., no DNSA added), this fluorescence intensity was used with the linear calibration plot to determine the amount of unmodified HCA** in the sample. Dividing this concentration by the total concentration of protein (as measured by UV spectroscopy), gave the percentage of contamination by unmodified HCA**.

\section{Determination of Dissociation Constants of Ethox and SA-OMe for HCA**_}

$\mathrm{SCH}_{2} \mathrm{CO}_{2}{ }^{-}$by Competition with DNSA. To the wells of a black microwell plate were added dilutions of Ethox or SA-OMe, DNSA to a final concentration of $5 \mu \mathrm{M}$, and $\mathrm{HCA}^{* *}-\mathrm{SCH}_{2} \mathrm{CO}_{2}{ }^{-}$ to a final concentration of $25-50 \mathrm{nM}$ in $200 \mu \mathrm{L}$ of $20 \mathrm{mM}$ sodium phosphate buffer $\mathrm{pH} 7.5$. The plate was allowed to incubate covered (to prevent photobleaching of DNSA) at $25^{\circ} \mathrm{C}$ for $1 \mathrm{~h}$. The fluorescence of the plate was measured (as above). The data were fit to eq S.2, which only makes the assumption that the concentration of free DNSA is equal to the concentration of total DNSA (a reasonable assumption given that $[\mathrm{DNSA}]_{\text {total }}>>[\mathrm{CA}]_{\text {total }}$ ), and is thus a simplification 
of the general equation derived by Wang et al. ${ }^{7}$

$$
\begin{gathered}
F=F_{\text {min }}+\left(F_{\text {max }}-F_{\text {min }}\right)\left(\frac{-A+\sqrt{A^{2}+4\left(K_{\mathrm{d}}{ }^{\mathrm{DNSA}}+\left(K_{\mathrm{d}}{ }^{\mathrm{DNSA}}\right)^{2} /[\mathrm{DNSA}]_{\text {total }}\right)[\mathrm{CA}]_{\text {total }} K_{\mathrm{d}}{ }^{\mathrm{L}}[\mathrm{L}]_{\text {total }}}}{2[\mathrm{CA}]_{\text {total }}\left(K_{\mathrm{d}}{ }^{\mathrm{DNSA}}+\left(K_{\mathrm{d}}{ }^{\mathrm{DNA}}\right)^{2} /[\mathrm{DNSA}]_{\text {total }}\right)}\right) \\
A=K_{\mathrm{d}}{ }^{\mathrm{DNSA}}[\mathrm{L}]_{\text {total }}-K_{\mathrm{d}}{ }^{\mathrm{DNSA}}[\mathrm{CA}]_{\text {total }}+K_{\mathrm{d}}{ }^{\mathrm{L}}[\mathrm{DNSA}]_{\text {total }}+K_{\mathrm{d}}{ }^{\mathrm{DNSA}} K_{\mathrm{d}}{ }^{\mathrm{L}}
\end{gathered}
$$

In this equation, $K_{\mathrm{d}}{ }^{\mathrm{DNSA}}$ and $K_{\mathrm{d}}^{\mathrm{L}}$ are the dissociation constants of the HCA-DNSA and HCA-L complexes, respectively, $[\mathrm{L}]_{\text {total }}$ is the total concentration of the ligand (Ethox or SA-OMe), and the other terms are as defined in eq S.1. The values of [DNSA $]_{\text {total }}$ and $K_{\mathrm{d}}{ }^{\text {DNSA }}$ were constrained to their known values, and the other parameters were allowed to vary to optimize the non-linear least squares fit (Origin). 

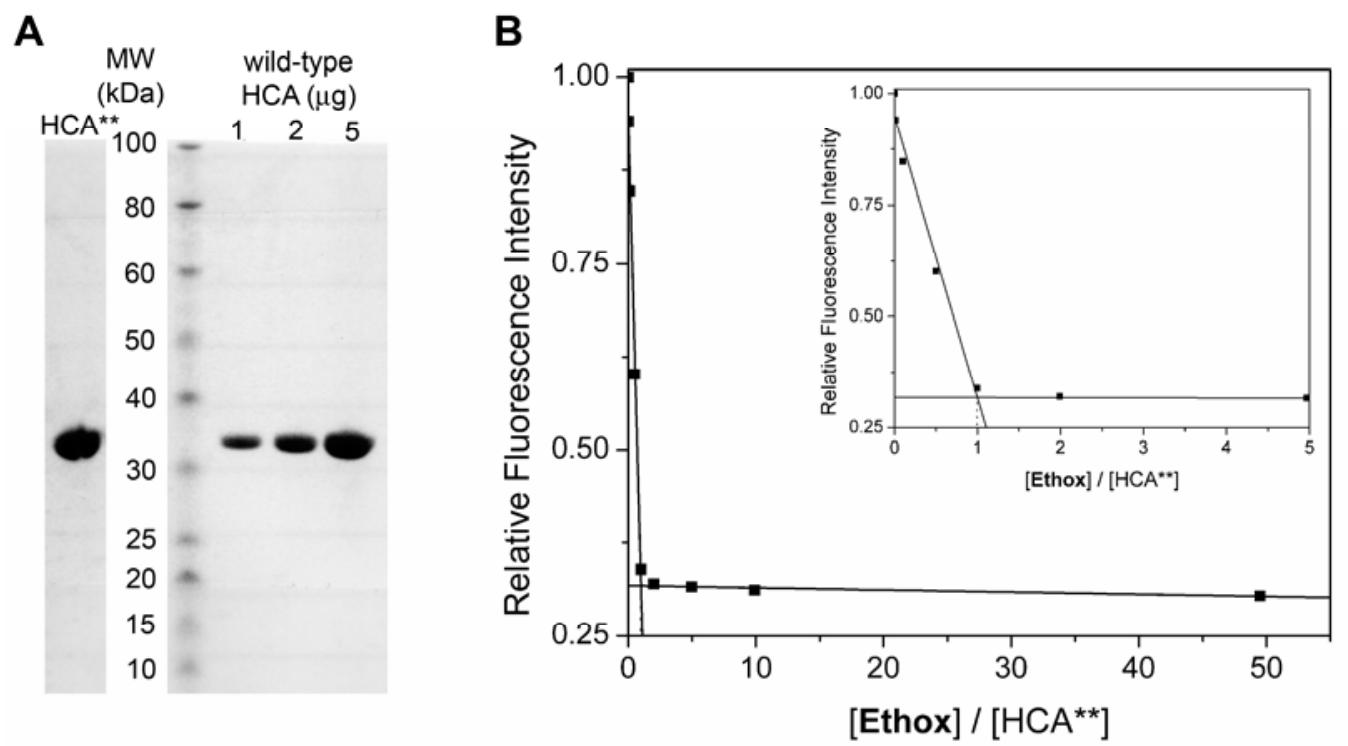

Figure S.1. Assessment of purity of HCA**. (A) SDS-PAGE of over-expressed and purified $\mathrm{HCA}^{* *}$. No contaminant proteins were present in the "overloaded" gel. The effective molecular weight of $\mathrm{HCA}^{* *}$ is the same as for commercially available wild-type HCA. The HCA** lane was digitally moved to be adjacent to the molecular-weight standards to facilitate comparison between lanes (care was taken to ensure that this lane was not manipulated vertically). (B) Sulfonamide-binding activity of $\mathrm{HCA}^{* *}$. The intrinsic fluorescence of $100 \mathrm{nM} \mathrm{HCA}{ }^{* *}$ was measured (excitation wavelength $=290 \mathrm{~nm}$, emission wavelength $=340 \mathrm{~nm}$ ) as the high-affinity, fluorescence quencher Ethox $\left(K_{\mathrm{d}}=0.20 \mathrm{nM}\right.$; see main text $)$ was titrated into the solution. The data are shown after background subtraction, correction for dilution and for the inner-filter effect $(<5 \%$ correction at these concentrations; see ref 36 of main text), and normalization to a maximum signal of unity. The $x$-coordinate at the intersection of the two straight lines (shown as a vertical dotted line) shows that all $(99.8 \%)$ of the $\mathrm{HCA}^{* *}$ can bind sulfonamides. The residual fluorescence $(\sim 0.30)$ at saturating concentrations of Ethox is consistent with a value reported by Kernohan et al. (ref 17 of main text). The inset shows a magnification of the main plot. 


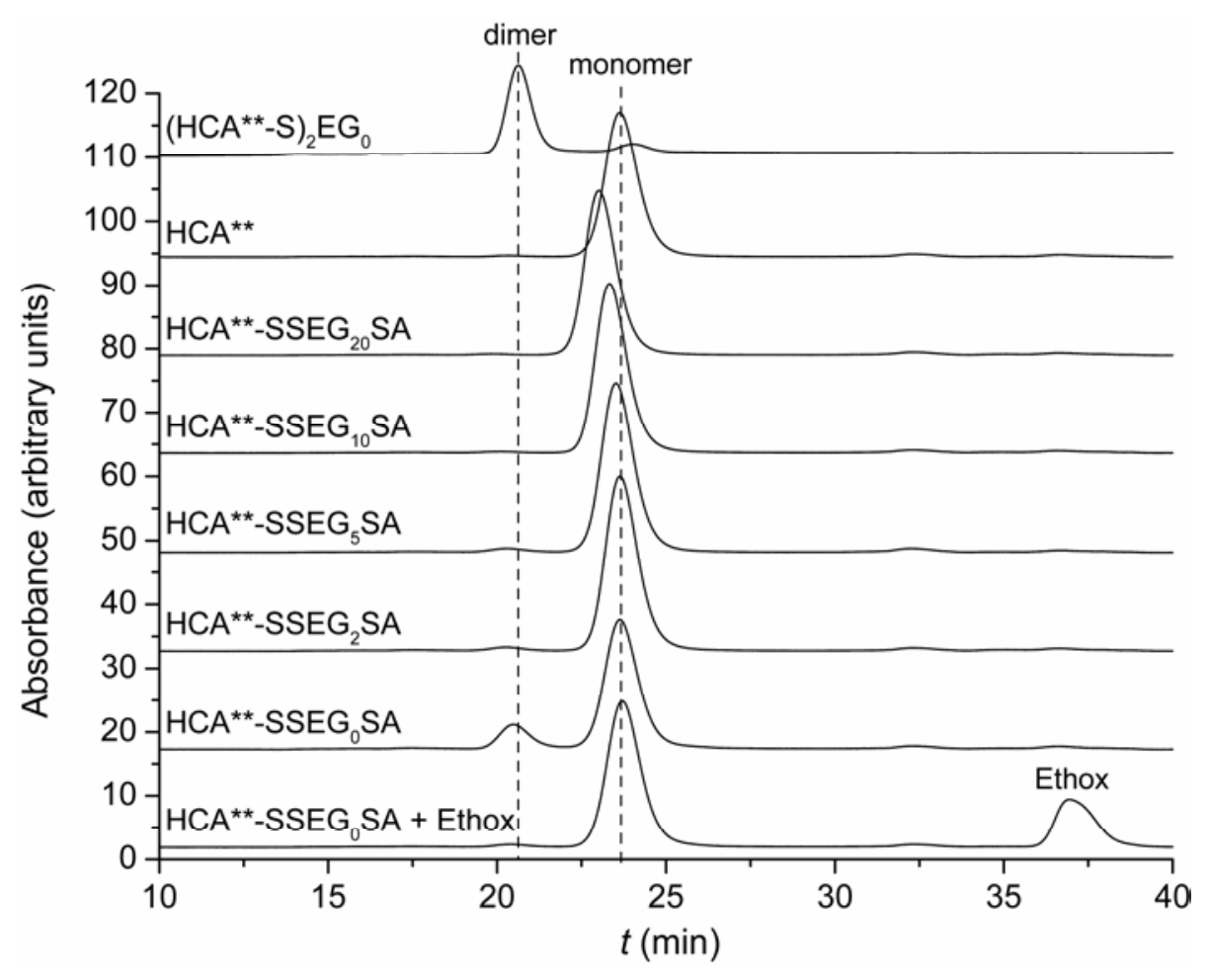

Figure S.2. Characterization of $\mathrm{HCA}^{* *}-\mathrm{SSEG}_{n} \mathrm{SA}$ proteins by size-exclusion high-performance liquid chromatography (SE-HPLC). Onto a Superdex 75 10/300 GL column (GE Healthcare Bio-Sciences, Piscataway, NJ) was injected $25 \mu \mathrm{L}$ of a $20 \mu \mathrm{M}$ sample of the indicated HCA** protein. The running buffer was $50 \mathrm{mM}$ Tris-sulfate $\mathrm{pH} 8.0$ with a flow rate of $0.5 \mathrm{~mL} \mathrm{~min}^{-1}$ and UV detection at $214 \mathrm{~nm}$. The $\left(\mathrm{HCA}^{* *}-\mathrm{S}\right)_{2} \mathrm{EG}_{0}$ sample was prepared by treating $\mathrm{HCA}^{* *}$ with a bis(maleimide) (Mack and Whitesides, manuscript in preparation) and serves as a control for the presence of $\mathrm{HCA}^{* *}$ dimer. $\mathrm{HCA}^{* *}-\mathrm{SSEG}_{0} \mathrm{SA}$ was incubated with a large excess of Ethox $(0.67$ $\mathrm{mM} ; \mathrm{HCA}^{* *}{ }_{-} \mathrm{SSEG}_{0} \mathrm{SA}+$ Ethox) and demonstrates that the dimer in the HCA**-SSEG $\mathrm{HA}_{0} \mathrm{SA}$ sample is non-covalently bound. The decrease in retention time $(t)$ of the monomer peak as the length $(n)$ of the linker of the $\mathrm{HCA}^{* *}{ }_{-} \mathrm{SSEG}_{n} \mathrm{SA}$ proteins increased is consistent with the increasing size of the $\mathrm{HCA}^{* *}{ }_{-} \mathrm{SSEG}_{n} \mathrm{SA}$ protein with increasing $n$. 


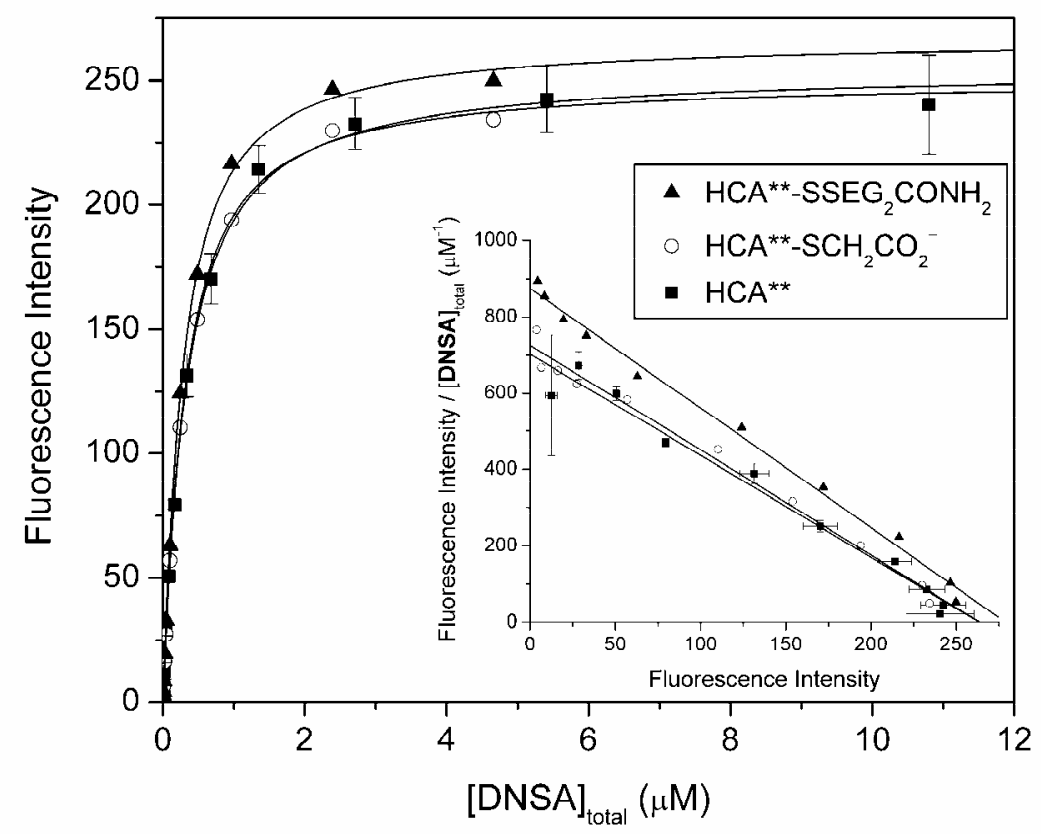

Figure S.3. Binding of dansylamide (DNSA) to $\mathrm{HCA}^{* *}, \mathrm{HCA}^{* *}-\mathrm{SCH}_{2} \mathrm{CO}_{2}{ }^{-}$, and $\mathrm{HCA}^{* *}{ }_{-}$ $\mathrm{SSEG}_{2} \mathrm{CONH}_{2}$. The fluorescence of the HCA-DNSA complex was followed (excitation wavelength $=290 \mathrm{~nm}$, emission wavelength $=460 \mathrm{~nm}$ ) as $50-100 \mathrm{nM}$ protein was treated with different concentrations of DNSA (refs 16 and 18 of main text). The data are shown after background subtraction. The solid curves are fits to the data using the full quadratic equation for binding (eq S.1; see Supporting Experimental Procedures and ref 18 of main text). The inset shows a Scatchard plot for the data; the assumption that $[\mathrm{DNSA}]_{\text {free }} \approx[\mathrm{DNSA}]_{\text {total }}$ is not true, which precludes the extraction of values of $K_{\mathrm{d}}$ from the linear fits. 


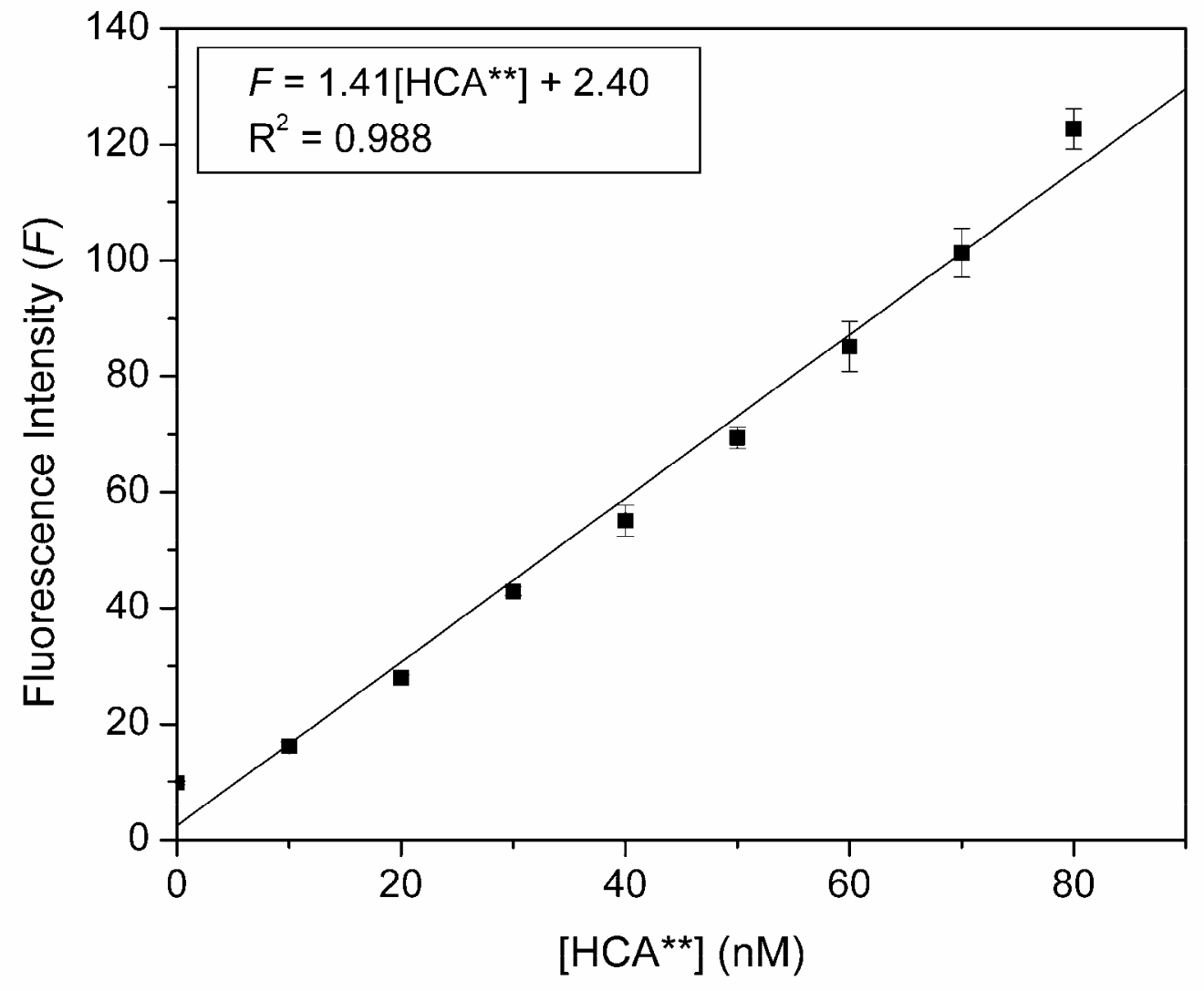

Figure S.4. Calibration plot to determine the concentration of unmodified $\mathrm{HCA}^{* *}$ in samples of $\mathrm{HCA}^{* *}-\mathrm{SSEG}_{n} \mathrm{SA}$. The fluorescence of wells containing $5 \mu \mathrm{M}$ of dansylamide (DNSA) and different concentrations of $\mathrm{HCA}^{* *}$ with an excitation wavelength $=290 \mathrm{~nm}$, emission wavelength $=460 \mathrm{~nm}$ (with $455 \mathrm{~nm}$ cut-off filter) and a linear fit to the data are shown (see Supporting Experimental Procedures for details). The error bars represent the maximum variation of one measurement from the mean of four replicates. 


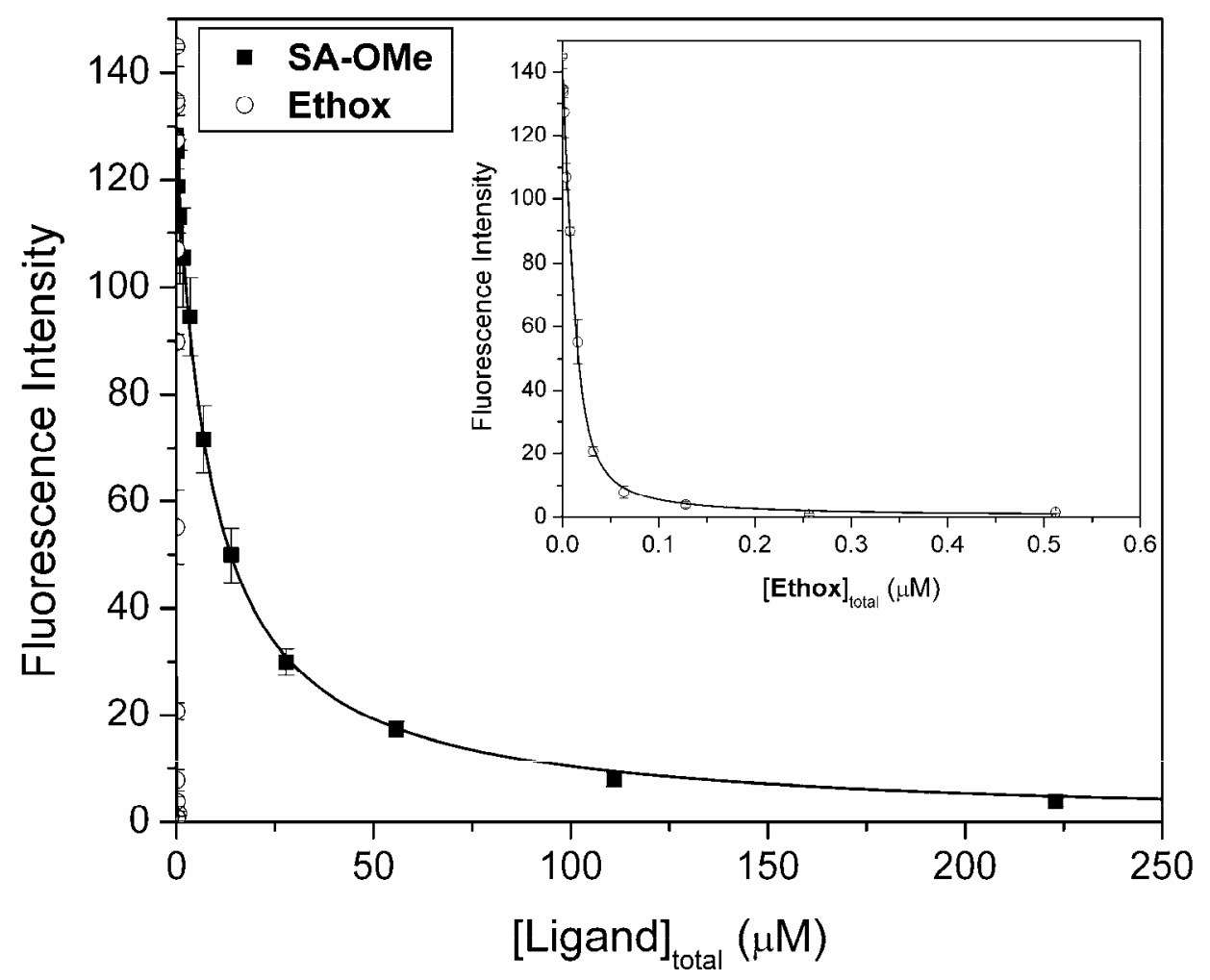

Figure S.5. Determination of dissociation constants of Ethox and SA-OMe for HCA**$\mathrm{SCH}_{2} \mathrm{CO}_{2}{ }^{-}$through competition with dansylamide (DNSA). The fluorescence of HCA-DNSA complex ( $50 \mathrm{nM}$ protein and $5 \mu \mathrm{M}$ DNSA) equilibrated with different concentrations of ligand (Ethox or SA-OMe) was measured (excitation wavelength $=290 \mathrm{~nm}$, emission wavelength $=460$ $\mathrm{nm}$; see refs 16,24 , and 25 of main text). The data are shown after background subtraction. The solid curves are fits to the data using the full quadratic equation for binding (eq S.2) but assuming that $[\mathrm{DNSA}]_{\mathrm{free}} \approx[\mathrm{DNSA}]_{\mathrm{total}}$ (see Supporting Experimental Procedures). The inset shows a magnification of the main plot to show the binding for the high-affinity ligand Ethox. 


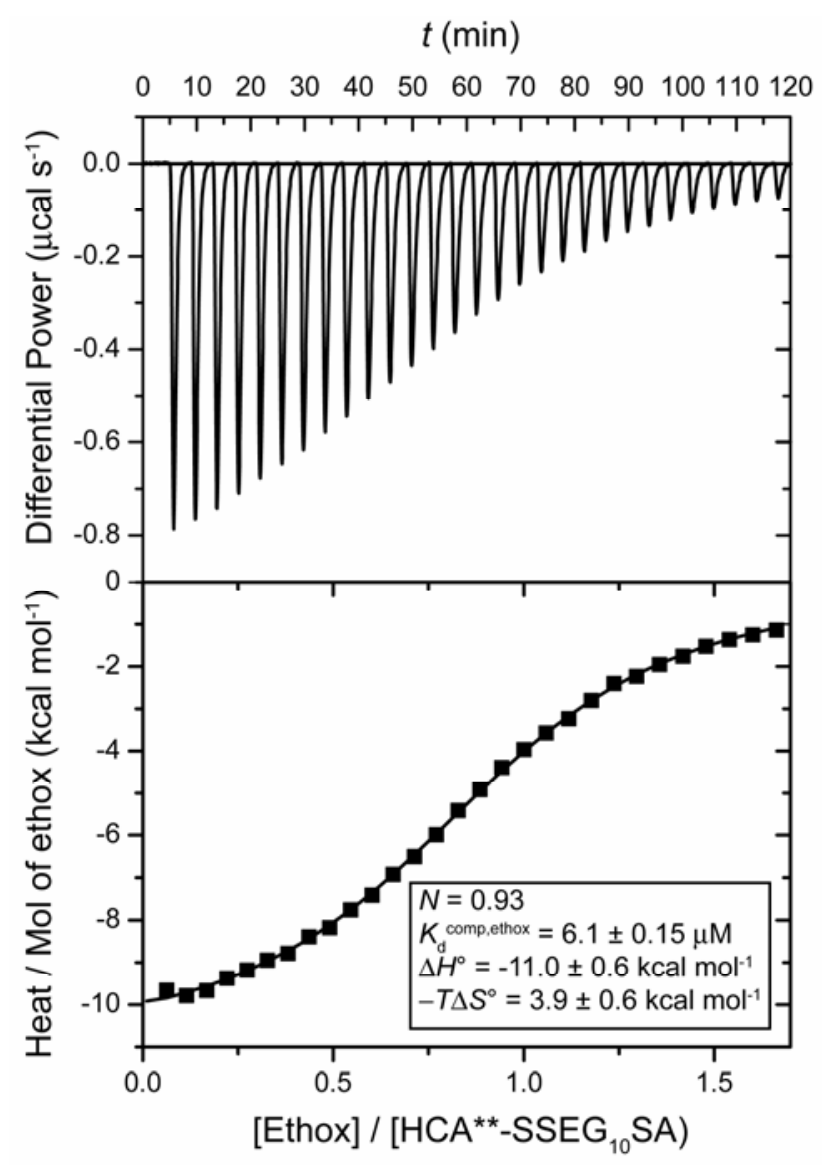

Figure S.6. Thermogram from ITC for the binding of Ethox to $\mathrm{HCA}^{* *} \mathrm{SSEG}_{10} \mathrm{SA}$ at $25^{\circ} \mathrm{C}$. The sample cell contained $60.5 \mu \mathrm{M} \mathrm{HCA}^{* *}-\mathrm{SSEG}_{10} \mathrm{SA}$ in $20 \mathrm{mM}$ sodium phosphate buffer $\mathrm{pH}$ 7.5 and $0.6 \%$ DMSO- $d_{6}(\mathrm{v} / \mathrm{v})$ (to solubilize the arylsulfonamide and to allow for NMR quantitation, see Experimental Section). The injection syringe contained $440 \mu \mathrm{M}$ Ethox in the same buffer. One injection of $2.0 \mu \mathrm{L}$ preceded 29 injections of $10.0 \mu \mathrm{L}$. The interval between injections was 4 min. Top panel: Data after baseline correction. Bottom panel: Data after peak integration, blank subtraction, and normalization to moles of injectant. The solid line shows a sigmoid fit to a single-site binding model (with the first datum omitted). The fitting parameters are shown in the box. 
A

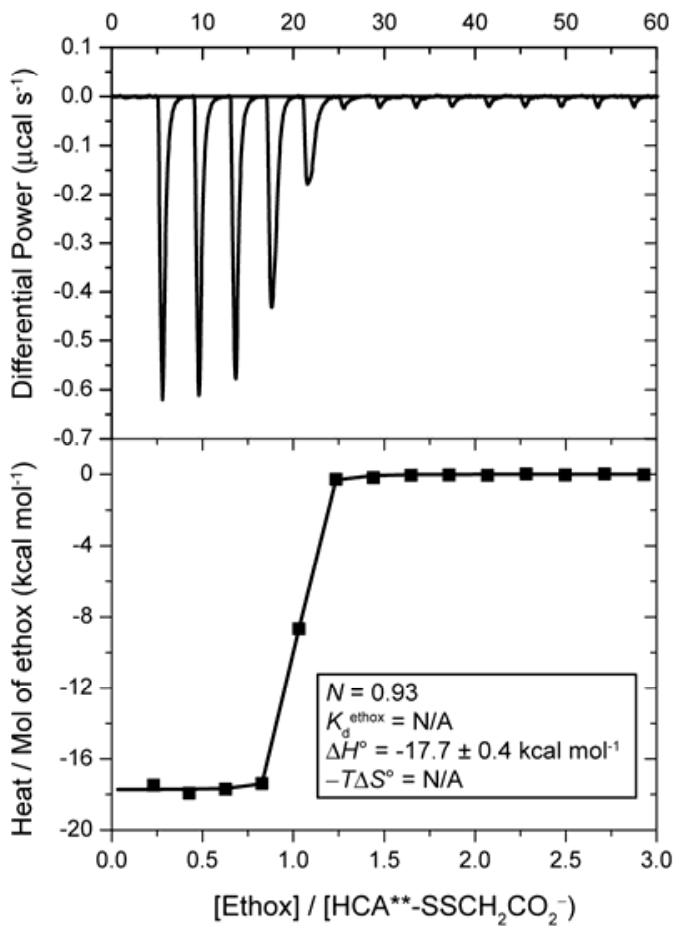

B $t(\min )$

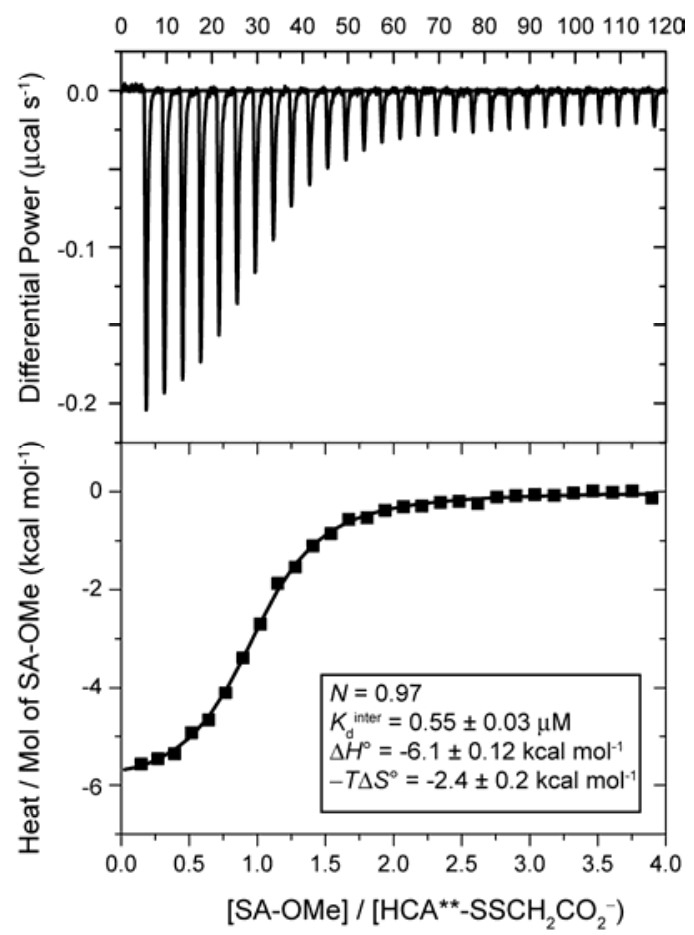

Figure S.7. Thermograms from ITC for the binding of Ethox (A) or SA-OMe $(\mathbf{B})$ to HCA**$\mathrm{SCH}_{2} \mathrm{CO}_{2}^{-}$at $25^{\circ} \mathrm{C}$. The sample cell contained $\sim 6 \mu \mathrm{M} \mathrm{HCA} * *-\mathrm{SCH}_{2} \mathrm{CO}_{2}^{-}$in $20 \mathrm{mM}$ sodium phosphate buffer $\mathrm{pH} 7.5$ and $0.6 \% \mathrm{DMSO}-d_{6}(\mathrm{v} / \mathrm{v})$ (to solubilize the arylsulfonamide and to allow for NMR quantitation, see Experimental Section). The injection syringe contained $\sim 120$ $\mu \mathrm{M}$ of the appropriate ligand in the same buffer. In (A), one injection of $2.0 \mu \mathrm{L}$ preceded 14 injections of $12.0 \mu \mathrm{L}$. In $(\mathbf{B})$, one injection of $2.0 \mu \mathrm{L}$ preceded 29 injections of $10.0 \mu \mathrm{L}$. The interval between injections was 4 min. Top panels: Data after baseline correction. Bottom panels: Data after peak integration, blank subtraction, and normalization to moles of injectant. The solid lines show sigmoid fits to a single-site binding model (with the first datum omitted). The fitting parameters are shown in the boxes. In (A), a reliable value for $K_{\mathrm{d}}$ could not be estimated by ITC because the affinity of Ethox for $\mathrm{HCA}^{* *}-\mathrm{SCH}_{2} \mathrm{CO}_{2}{ }^{-}$is too high to be measured directly (i.e., the thermogram lacks curvature and is a step function). 
Table S.1. Calculated and observed masses of $\mathrm{HCA}^{* *}$ proteins.

\begin{tabular}{lcc}
\hline Protein & Calculated mass (Da) & ESI-MS (Da) \\
\hline HCA $^{* *}$ & $29057^{a}$ & 29068 \\
$\mathrm{HCA}^{* *}{ }_{-} \mathrm{SCH}_{2} \mathrm{CO}_{2}{ }^{-}$ & $29138^{b}$ & 29151 \\
$\mathrm{HCA}^{* *}{ }_{-} \mathrm{SSEG}_{2} \mathrm{CONH}_{2}$ & $29419^{a}$ & 29428 \\
$\mathrm{HCA}^{* *}{ }_{-} \mathrm{SSEG}_{0} \mathrm{SA}$ & $29500^{a}$ & 29504 \\
$\mathrm{HCA}^{* *}{ }_{-} \mathrm{SSEG}_{2} \mathrm{SA}$ & $29588^{a}$ & 29592 \\
$\mathrm{HCA}^{* *}{ }_{-} \mathrm{SSEG}_{5} \mathrm{SA}$ & $29720^{a}$ & 29725 \\
$\mathrm{HCA}^{* *}{ }_{-} \mathrm{SSEG}_{10} \mathrm{SA}$ & $29940^{a}$ & 29945 \\
$\mathrm{HCA}^{* *}{ }_{-} \mathrm{SSEG}_{20} \mathrm{SA}$ & $39381^{a}$ & 39385 \\
\hline
\end{tabular}

${ }^{a}$ Calculated by summing the mass of $\mathrm{HCA}^{* *}$ lacking both the $\mathrm{Zn}^{2+}$ cofactor and the first residue (Met), which is believed to be post-translationally removed by E. coli (ref 29 of main text) and the mass of the coupled molecule. ${ }^{b}$ Calculated for $\mathrm{HCA}^{* *}$ as in $a$, but including the mass of a $\mathrm{Na}^{+}$ion. ${ }^{c}$ Deconvoluted mass of the major peak from electrospray ionization mass spectrometry (ESI-MS). Two minor peaks with masses greater by $\sim 25 \mathrm{Da}$ and $\sim 62 \mathrm{Da}$ than the major peak were present in all samples; these peaks presumably represent the $\mathrm{Na}^{+}$-adduct and $\mathrm{Zn}^{2+}$-adduct (holo-CA), respectively. ESI-MS was performed on a Sciex triple quadrupole mass spectrometer (Applied Biosystems, Foster City, CA) as previously described by Shaw et al. ${ }^{8}$ Spectra were deconvoluted and a mass spectrum was generated using Max Entropy software (part of MassLynx from Waters, Milford, MA). Mass values were determined from at least six charge states.

\section{Supporting References}

1. Chu, Y. H.; Avila, L. Z.; Biebuyck, H. A.; Whitesides, G. M. J. Med. Chem. 1992, 35, 2915-2917.

2. Sigal, G. B.; Mammen, M.; Dahmann, G.; Whitesides, G. M. J. Am. Chem. Soc. 1996, 118 , 3789-3800.

3. Ilies, M. A.; Masereel, B.; Rolin, S.; Scozzafava, A.; Câmpeanu, G.; Cîmpeanu, V.; Supuran, C. T. Bioorg. Med. Chem. 2004, 12, 2717-2726.

4. Carpino, L. A. J. Am. Chem. Soc. 1993, 115, 4397-4398.

5. Snider, B. B.; Ahn, Y.; O'Hare, S. M. Org. Lett. 2001, 3, 4217-4220.

6. Rink, H. Tetrahedron Lett. 1987, 28, 3787-3790.

7. Wang, Z.-X. FEBS Lett. 1995, 360, 111-114.

8. Shaw, B. F.; Durazo, A.; Nersissian, A. M.; Whitelegge, J. P.; Faull, K. F.; Valentine, J. S. J. Biol. Chem. 2006, 281, 18167-18176. 